\title{
The role of social and technical excludability for the success of impure public good and common pool agreements The case of international fisheries ${ }^{\text {th }}$
}

\author{
Michael Finus $^{\mathrm{a}, *}$, Raoul Schneider ${ }^{\mathrm{b}}$, Pedro Pintassilgo $^{\mathrm{c}}$ \\ a University of Graz, Austria and University of Bath, Bath, UK \\ ${ }^{b}$ Department of Economics, Ulm University, Ulm, Germany \\ ${ }^{c}$ Faculty of Economics and CEFAGE, University of Algarve, Faro, Portugal
}

\section{A R T I C L E I N F O}

\section{Article history:}

Received 22 August 2017

Received in revised form 30 August 2019

Accepted 17 September 2019

Available online 29 September 2019

\section{JEL classification:}

$\mathrm{C} 72$

F53

H87

Q22

Keywords:

Pure and impure public goods and common pool resources

Technical and socially constructed

non-excludability

Benefit-cost duality of public goods and

common pool resources

Property rights

Shared fish stocks

Regional fisheries management

organizations

Free-riding

\begin{abstract}
A B S T R A C T
We argue that international fisheries are a prime example to study the incentive structure of forming impure public good and common pool agreements. We consider a fully integrated multiple zone model, in which zones are linked through density-dependent migration. The incentive to accede to Regional Fishery Management Organizations (RFMOs) is related to multiple characteristics. Firstly, the relative patch sizes of the high seas, which is the internationally (publicly) accessible domain, compared to exclusive economic zones, which are state-owned (privately owned). This can be related to the degree of socially constructed excludability. Secondly, the intensity of fish migration between various zones, which can be related to the degree of technical excludability. Thirdly, the growth rate of the resource, which can be interpreted as the degree of rivalry, with a low (high) degree of rivalry approximating public good (common pool) features. We show that, generally, excludability reduces freeriding incentives but also the need for cooperation, a variant of the "paradox of cooperation". Moreover, we show that the benefit-cost duality between public goods and common pool resources generally holds except for some extreme parameter values for which a low degree of rivalry fosters the success of cooperation. Finally, through a variation of the diffusion matrix, we can also analyze a closed as well as a sink-source system.
\end{abstract}

(c) 2019 Elsevier B.V. All rights reserved.

\section{Introduction}

A central aspect in the theory of public goods is to understand the incentive structure that leads to the underprovision of public goods as well as the possibilities of rectifying this. The incentive structure can be broadly related to the properties of public goods, which are usually associated with two distinguishing features: non-excludability and non-rivalry, which can be traced back to the seminal work of Samuelson (1954) and Musgrave (1959). By varying the degree of excludability and

\footnotetext{
is We are very grateful to two anonymous reviewers and the editor, Professor Kaffine, for very helpful comments on a previous version of the paper

* Corresponding author at: University of Graz, Department of Economics, Universitätsstraße 15, 8010 Graz, Austria.

E-mail address: michael.finus@uni-graz.at (M. Finus).
} 
Table 1

Classification of Impure Public Goods.

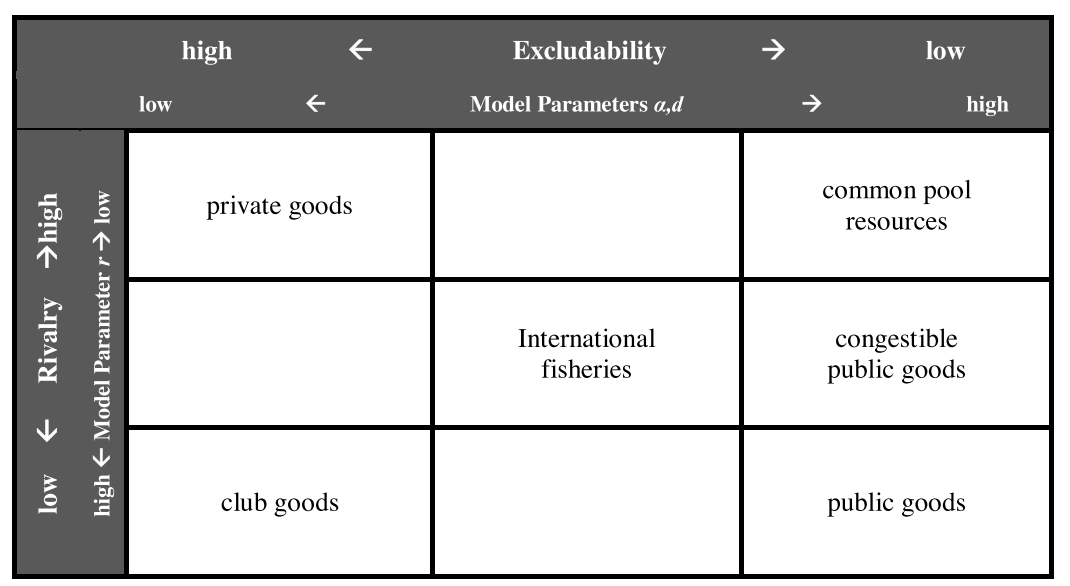

rivalry, various mixed forms of impure public goods emerge as illustrated in Table 1 (e.g., Cornes and Sandler, 1994 and Kaul and Mendoza, 2003).

In terms of excludability, the expectation is that the higher the degree of excludability, the closer are non-cooperative equilibrium and optimum, but also the smaller are the gains from cooperation. Kaul and Mendoza (2003) emphasize that the perception of what is public and what is private has changed significantly over time. They distinguish between the intrinsic properties of a good, to which for instance the so-called technical excludability belongs, and the properties assigned by society to them, to which they refer to as so-called socially constructed excludability. Whereas the degree of technical excludability can be regarded as given (though potentially subject to technological change as in the case of encryption in broadcasting), socially constructed excludability is determined by the establishment and enforcement of property rights.

In terms of rivalry, the expectation appears to be less clear-cut. On the one hand, Sandler and Arce (2003) convincingly show the benefit-cost duality of pure public goods (with strategies being provision levels) and common pool resources (with strategies being exploitation levels). In the public good game, the costs are private and the benefits from provision are public. In the commons game, the reverse is true, the benefits are private and the costs from exploitation are public. Thus, the economics and incentives should be the same in both settings and hence the degree of rivalry should not matter. On the other hand, despite their formal proof of equivalence, the authors conclude informally that there is a difference: in politics, it would be easier to establish joint action in public good games (i.e., cooperatively providing the public good) than joint inaction in commons games (i.e., cooperatively reducing the level of harvesting). This would suggest that rivalry, as the only distinguishing feature between public goods and common pool resources, would matter.

To the best of our knowledge, there is no formal model capturing the following three aspects simultaneously: 1) different degrees of socially constructed and technical excludability as well as rivalry, 2) an analysis of their effect on equilibrium public good provision and common pool resource use levels and 3) a test for the possibility to establish full or partial cooperation in a non-cooperative model of coalition formation.

In terms of the first aspect, we view international fisheries as one of the few and particularly interesting examples where all properties are simultaneously present. ${ }^{1}$ The degree of socially constructed and technical excludability can be parameterized along the entire horizontal spectrum in Table 1. In our model, parameter $\alpha$ measures the portion of the total fishing ground which is publicly accessible by all fishing states (common property), the so-called high seas, and $1-\alpha$ is the portion of the total fishing ground which is privately owned by coastal states, the so-called Exclusive Economic Zones (EEZs), as established by the UN Convention on the Law of the Sea in $1982 .{ }^{2}$ Thus, the larger $\alpha$, the smaller is the degree of socially constructed excludability. The parameter $d$ determines the intensity of fish migration between different zones. The larger $d$, the smaller

\footnotetext{
1 The sharing of water resources has similar features. Socially constructed excludability can be established through property rights and technical excludability may vary through the diversion of rivers and the erection of dams. However, many other examples feature only some properties mentioned above though not all. For instance, the acid rain game allows capturing various degrees of technical excludability through the emission transportation matrix (e.g. Mäler, 1994 and Sandler, 1998), but since national boundaries are given, the degree of socially constructed excludability is not an issue. The same applies to the classical example of a pure public good game, climate change mitigation, even if we recognize the privatizing effects of ancillary or co-benefits of improved local air quality from climate mitigation as analyzed for instance in Markandya and Rübbelke (2004). In the case of the exploration of the natural resources in the Antarctic (e.g., oil, gas and minerals), after property rights were properly defined and enforced, excludability would be perfect as technical excludability can be regarded as perfect. In terms of rivalry, all examples are only located at one extreme of the spectrum: acid rain and climate change exhibit no rivalry at all whereas for non-renewable resources rivalry is perfect.

2 In terms of terminology, in our setting "privately owned" and "privatization" means the allocation of property rights to states - the sole actors or players in our international fishery game. In the fishery literature, mainly with a national or regional focus, these terms are sometimes also used for the allocation of fishing quotas to fishermen. We abstract from these national details. See Section 4.4 for the qualification of our assumptions.
} 
is the degree of technical non-excludability. Also the degree of rivalry can be parameterized along the entire vertical axis in Table 1 through the growth rate of the fish stock, which is parameter $r$ in our model. This allows us to study how technical and socially constructed excludability and the growth rate (apart from some other parameters) affect the success of fishery agreements.

In terms of the second aspect, we measure the level of underprovision of the impure public good (i.e., "preservation of fish stocks") as the difference between the fully cooperative, partially cooperative and non-cooperative equilibrium, physically in terms of stock levels and monetarily in terms of payoffs. Differences are related to the properties of the public good/common pool resource and important economic and biological parameters that determine the production process.

In terms of the third aspect, in the tradition of the literature on international environmental agreements (IEAs) ${ }^{3}$ and the literature on international fishery agreements (IFAs) ${ }^{4}$, we study the formation of self-enforcing agreements as a means to mitigate free-riding with a non-cooperative coalition model. However, the IEA-literature has almost exclusively restricted attention to a global emission game ${ }^{5}$ (i.e., pure public bad) and the IFA-literature considered a renewable common resource with only one jurisdiction (i.e., pure common pool resource) ${ }^{6}$ In contrast, we allow for several jurisdictions, i.e., some parts of the ocean may become privately owned through the declaration of EEZs. Moreover, among EEZs and the high seas there may be links through the migration of fish. Thus, by varying the degree of socially constructed and technical excludability, we vary the degree of "purity", i.e., we cover the spectrum from pure, impure to private.

Our model is based on the classical Gordon-Schaefer model (Gordon, 1954) which is extended to account for migration between different fishing grounds as considered for instance in Sanchirico and Wilen (1999, 2005). We focus our discussion on a fully integrated model with bilateral links among all zones and a density-dependent diffusion process. A special case is the closed patch model if there is no diffusion between zones. We finally consider a sink-source model with unilateral diffusion process as an extension. We show that, generally, establishing RFMOs is difficult and always fails in a sink-source model. Moreover, excludability reduces free-riding incentives but also the need for cooperation, a variant of the "paradox of cooperation". Moreover, the benefit-cost duality between public goods and common pool resources generally holds except for some extreme parameter values for which a low degree of rivalry fosters the success of cooperation.

The paper proceeds as follows. In Section 2, we provide a brief background on the historical development of the management of international fisheries and the establishment of cooperative agreements. In Section 3, we introduce the bioeconomic model including the two-stage coalition formation model. Section 4 describes the model specifications and our solution procedure. Sections 5, 6 and 7 discuss our results for the fully integrated model with density-dependent diffusion. According to the sequence of backward induction, we first discuss results of the second stage (Section 5), then of the first stage (Section 6) and finally pull results of both stages together in Section 7. Section 8 discusses briefly three extensions: i) the possibility of excluding non-RFMO members from fishing in the high seas, ii) an alternative agreement formation process and iii) a sink-source model with uni-directional diffusion. Section 9 concludes.

We would like to point out at the outset that although our model relates to international fisheries, our aim is to remain as general as possible with reference to the literature on public goods and hence we abstract from technical details investigated in some of the literature on fisheries.

\section{Historical background on international fishery management}

The Food and Agriculture Organization of the United Nations (FAO) estimates that harvests from internationally shared fish stocks ${ }^{7}$ account for as much as one third of global marine capture fishery harvests (FAO, 2010 and Munro et al., 2004 ). These stocks are estimated to be particularly vulnerable and are reported to be heavily overexploited or even depleted in McWhinnie (2009).

For a long time, concern mainly focused on the preservation of coastal fishing grounds. Some governments started to declare unilaterally EEZs, thus evicting all foreign fleets from what they claimed to be their private property. The 1982 UN

\footnotetext{
3 The literature on IEAs goes back to Barrett (1994) and Carraro and Siniscalco (1993) and has grown immensely in recent years. For a recent survey and a collection of the most influential articles see Finus and Caparros (2015).

4 Stability of fishery agreements has been modelled as cooperative (e.g., Kennedy, 2003 and Lindroos, 2004) or non-cooperative coalition games (e.g., Kwon, 2006; Lindroos, 2008; Miller and Nkuiya, 2016; Pintassilgo and Lindroos, 2008, and Pintassilgo et al., 2010), but also as a dynamic fishery game with enforcement through punishment (e.g., Hannesson, 1997 and Tarui et al., 2008). For a recent survey see Pintassilgo et al. (2015).

5 Exceptions are for instance Mäler (1994) and Finus and Tjøtta (2003) in the context of a repeated acid rain game (i.e., impure public bad), though they only focus on the stability of the grand coalition and do not exploit the relation between transportation coefficients (i.e., measuring the degree of technical excludability) and the success of cooperation as we do.

6 Already Crutchfield (1964), p. 216, based his call for international cooperation on the observation that migration of fish poses a natural limit to the privatization of fishery resources: “[...] the fish themselves seem indisposed to accept such [privatizing] solutions." Spatial externality models without coalition formation have been studied for instance by Costello and Polasky (2008); Flaaten and Mjølhus (2005); Kvamsdal and Sandal (2008); Pezzey et al. (2000). The only spatial model with coalition formation of which we are aware is Punt et al. (2013). They consider a marine protected area (MPA) in the high seas. However, no migration is considered between the MPA and the fishing grounds. The authors conclude that for symmetric players no coalition is stable as this is the case without MPAs.

7 According to FAO's classification there are four categories of shared fish stocks: transboundary stocks (resources that cross the EEZs of two or more coastal states); highly migratory stocks (found both within the EEZs and the adjacent high seas and highly migratory in nature); straddling stocks (also cover both EEZs and the high seas but are more stationary); discrete high seas stocks (found exclusively in the high seas).
} 
Convention on the Law of the Sea (UNCLOS) harmonized and legalized the various unilateral declarations in assigning the right to coastal states to establish EEZs, comprising 200 nautical miles (Munro, 1982). After some initial success, it became clear that further action was required as the significance of high seas fisheries had been underestimated. In particular, technological progress, such as the introduction of fish carriers and vessels with on board fish processing equipment, had made the resources of the high seas more accessible. Increasing awareness of overfishing led to the 1995 UN Fish Stocks Agreement. Under this agreement, shared fish stocks are to be managed on a region by region basis by Regional Fisheries Management Organizations (RFMOs). There are currently around 20 RFMOs in force as for example the Northwest Atlantic Fisheries Organization (NAFO) and the North East Atlantic Fisheries Commission (NEAFC). ${ }^{8,9}$

\section{Model}

\subsection{Preliminaries}

The formation of cooperative agreements is typically modelled as a two-stage game in which players choose first their membership and then their economic strategies. (For an exception, see, e.g., McCarthy et al., 2001 and Sampson and Sanchirico, 2019.) The game is solved by backwards induction. The typical assumption in the second stage is that players which join an agreement chose their economic strategies cooperatively whereas non-members non-cooperatively. That is, members to an agreement internalize all externalities among their group. Consequently, if no agreement forms, this corresponds to the classical Nash equilibrium whereas if all players join the agreement (i.e., the grand coalition forms), this represents the social optimum. The typical assumption in the first stage is that - based on the payoff derived from the second stage - an agreement is stable if no member wants to leave and no non-member wants to join.

The details of the two stages can be modelled in many ways (see, e.g., Finus and Caparrós, 2015). The "ideal" model would allow for a dynamic coalition formation process in both stages: players can revise their membership decision as well as their economic strategies over time. That is, (i) current harvests affect tomorrow's fish stocks across the economics zones; (ii) countries reconsider regularly their fishing quotas and their decision to voluntarily join or leave a RFMO; (iii) such fishing quotas and membership decisions are reconsidered contingent on stock levels. Such an ideal model is technically extremely challenging, and would be even more so in our context with several zones and migration. It is for this reason that except for Rubio and Ulph (2007) in the context of climate change and Miller and Nkuiya (2016) in the context of a fishery (without zoning and migration), all coalition models of which we are aware have made some simplifying assumptions: either the first or the second stage is static.

Finus and Rundshagen (2006) and Finus et al. (2014) model a sequential coalition formation process in stage 1, but assume a one-shot payoff derived from economic strategies in stage 2 . We will briefly report on two interesting extensions to our model regarding the first stage in Section 8.

In contrast, Eyckmans and Finus (2006); Eyckmans and Tulkens (2003) and Rubio and Casino (2005) in the context of climate change and Kwon (2006) in the context of fisheries (with one single zone) assume a one-shot decision in terms of membership, based on the net present value of the equilibrium strategies in a dynamic game. Clearly, this approach cannot capture the interesting feature of how the transition from one steady state to another over time affects stability of coalitions. Transitions disappear in the summation over time. Hence, may be not surprisingly, qualitative results of the net present value and steady-state payoff approach are very similar. For instance, in a fishery with symmetric players and standard assumptions, no stable agreement exists if the number of players is larger than two as shown in Pintassilgo and Lindroos (2008) in the steady state payoff model and in Kwon (2006) in the net present value model. ${ }^{10}$ It is for this reason that we model the second stage using the simple static Gordon-Schaefer model (see also Flaten and Mjølhus, 2005; Kvamsdal and Sandal, 2008, Pezzey et al., 2000, Punt et al., 2013; Lindroos, 2008, Lindroos, 2008 and Long and Flaaten, 2011), which basically assumes that the system is always in a steady state.

Taken together, we assume a simple coalition formation process in which countries choose simultaneously whether to join an RFMO in a first stage and thereafter simultaneously chose their equilibrium economic strategies in the second stage based on the simple mechanics of the static version of the classical Gordon-Schaefer model (Gordon, 1954 and Schaefer, 1954). This model is extended to account for different fishing zones and the migration of fish stocks across zones. In the following, the biological model is developed in Section 3.2, the economic model is laid out in Section 3.3, which captures the strategic behavior among states under various assumptions about the degree of cooperation; it also includes the definition of stable cooperative arrangements.

\footnotetext{
${ }^{8}$ For an overview see for instance Munro et al. (2004) and FAO online (2012),

${ }^{9}$ Reports that seriously and consistently measure the effectiveness of RFMOs are scarce. Some evidence is gathered for instance in High Seas Task Force (2006) and Lodge et al. (2007). As Willock and Lack (2006), p. 32, write: "There appears to be some reluctance to, or at least nervousness about, establishing a standard set of performance indicators against which RFMOs might be held accountable and their performance compared."

${ }^{10}$ Similarly, in climate change, for a linear-quadratic payoff function, a stable agreement consist of three players in the static payoff model (Barrett, 1994) and the net present value model (Rubio and Casino, 2005).
} 


\subsection{Biological model}

We assume that a given number of players $N$ exploit a shared natural resource of size $k{ }^{11}$ In the context of biological populations, $k$ is called the carrying capacity of the biological system, which we interpret as the geographical size of the system as in Flaaten and Mjølhus (2005); Pezzey et al. (2000) and Sanchirico and Wilen (1999). In our context, the resource is the fish stock and the biological system is the ocean. Parts of the system may have been privatized through the establishment of exclusive economic zones. Hence, there are two types of geographical zones: the high seas, abbreviated HS, the common property where all states can fish (Art. 87, UNCLOS 1982), and the exclusive economic zones, abbreviated $E E Z_{i}$, the private properties with exclusive fishing rights of coastal state $i$ (Art. 56, UNCLOS 1982).

Denoting the entire size of the system by $k_{\text {tot }}$ and the share of the resource for which no private property rights have been established by $\alpha$, we define:

$$
k_{H S}=\alpha k_{t o t} \quad \text { and } \quad k_{E E Z}=\frac{1-\alpha}{N} k_{t o t}
$$

assuming for simplicity the same carrying capacity in each $E E Z_{i}$. Henceforth, $\alpha \in[0,1]$ measures the relative size of the different patches. It will become apparent that in the fully integrated model with density-dependent diffusion, this parameter can be exclusively related to the degree of socially constructed excludability with $\alpha=0$ implying perfect socially constructed excludability and $\alpha=1$ perfect non-excludability at the respective limits (see Table 1 ). In the context of a sink-source model, such simplification is not valid. We encourage the reader to consult Appendix 3 in the Supplementary material, which explains under which conditions the relative patch sizes $\alpha$ can be linked to the degree of socially constructed excludability.

In our context, players are sovereign countries engaging in fishing, i.e., coastal states, with exclusive access to their own EEZ and a shared access to the high seas. We abstract from the fact that EEZs could be of different size and that so-called distant water fishing states without EEZ engage in fishing in the high seas.

The steady-state condition is given by a system of $N+1$ equations:

$$
\mathrm{G}(\mathrm{X})-\mathrm{H}(\mathrm{X}, \mathrm{E})+D \mathrm{X}=0
$$

with $X=\left(X_{1}, \ldots, X_{N}, X_{H S}\right)$ the vector of fish stocks in the various zones ${ }^{12}$, the vector of efforts, $E=\left(E_{E E Z_{1}}, \ldots, E_{E E Z_{N}}, E_{H S}\right)$ which is a physical measure of input, ${ }^{13}$ e.g., time spent fishing, $G(X)$ the vector of growth functions, $H(X, E)$ the vector of harvest levels, $D$ a diffusion matrix accounting for the migration of fish stocks across zones, and 0 a vector of zeros with size $N+1$. Hence, Eq. (2) states that in the steady state, growth and harvest are balanced, accounting additionally for incoming and outgoing stock flows through migration, such that the stock in each zone remains constant. Clearly, the higher growth, the more can be harvested in equilibrium and hence the lower is the degree of rivalry.

The components of $G=\left(G_{1}, \ldots, G_{N}, G_{H S}\right)$ describe growth of the stock in each zone, assuming that growth requires an initial population, $G_{i}\left(X_{i} \mid X_{i}=0\right)=0, i=1, \ldots, N, H S$, is positive as long as the carrying capacity has not been reached, $G_{i}\left(X_{i} \mid X_{i}<k_{i}\right)>0$, and stops at the carrying capacity, $G_{i}\left(X_{i} \mid X_{i}=k_{i}\right)=0 .{ }^{14}$ The components of $H=\left(H_{E E Z_{1}}, \ldots, H_{E E Z_{N}}, H_{H S}\right)$ are the harvest levels in each zone which depend both on the vector of stocks, $X$, and the vector of efforts, $E$, i.e., $H(X, E)$. $H_{E E Z_{1}}, \ldots, H_{E E Z_{N}}$ are the harvest levels of each country in its own EEZ; $H_{H S}$ is the aggregate harvest level of all countries in the high seas. Due to the migratory behavior of fish stocks, harvest from each zone generally depends on all fishing efforts. Finally, the diffusion matrix $D=\left(d_{i j}\right), i, j \in\{1,2, . ., N, H S\}$ contains all information needed to describe the diffusion process; it is not only important whether zone $i$ and zone $j$ are connected via diffusion $\left(d_{i j} \neq 0\right.$ and $\left.d_{j i} \neq 0\right)$ but also the strength of interaction, i.e., the absolute value of $d_{i j}$ and $d_{j i}$, as well as the sign, with negative values of $d_{i j}$ indicating net outgoing diffusion from zone $i$ to $j$ and positive values net incoming diffusion. ${ }^{15}$

From a conceptual point of view, migration determines the degree of technical non-excludability. As it is virtually impossible to erect fences in the ocean to separate fish stocks, it is technically not feasible for a country to exclude other countries entirely from benefiting from its fishery resources. Thus, there can be some degree of non-excludability, stemming from migration, even if socially constructed excludability is perfect, i.e., all property rights have been allocated to states, $\alpha=0$, and these rights are perfectly enforceable through the declaration of EEZs (i.e., we rule out illegal fishing in EEZs).

\footnotetext{
11 Hence, in our setting, non-cooperative behavior is not identical to what is called open access in the fishery literature as long as $N$ is finite. That is, rents are lower in the non-cooperative than in the cooperative equilibrium, but rents will not completely dissipate through entry.

12 We talk about different stocks in different zones, but one could also talk about different shares of the total stock as we consider only one species. In any case, if we talk about the total stock, we mean the sum of the components of the vector $X$. The total stock as well as its allocation is a result of equilibrium effort levels as described in Section 3.3 and the exogenous parameters of the model, like for instance the allocation, diffusion and cost parameter.

13 The aggregate effort in the high seas, $E_{H S}$, is the sum of effort levels of all countries, $E_{H S}=\sum_{i=1, \ldots N} E_{H S_{i}}$. Similarly, for harvest levels, $H_{H S}=\sum_{i=1, \ldots, N} H_{H S_{i}}$ as the high seas is accessible by all countries and is viewed as one zone. A modification of this assumption is considered in Section 8.1.

${ }^{14}$ Appendix 3 in Supplementary material explains that no such concept as aggregate growth over all zones exists, growth is only defined in a particular zone.

${ }^{15}$ It would be misleading to think of the diffusion matrix being similar to the transportation matrix known from transboundary pollution as we explain in more detail Section 4.2 and in Appendix 2 in the Supplementary material. The entries in the transportation matrix are the shares of emissions of country $i$ which are deposited in country $j$. Hence, shares lie between 0 and 1 . The entries in the diffusion matrix reflect the speed and direction of migration between zones. Thus, not only units are different but entries can be positive and negative and are not bounded by 1 . Note that the steady-state condition does not require diffusion to vanish but only to be balanced by growth and harvest in every zone.
} 


\subsection{Economic model}

Each player receives an economic rent or, as we call it, payoff $\Pi_{i}$ that is obtained from the harvest extracted from the private and public resource:

$$
\Pi_{i}=p \cdot\left(H_{E E Z_{i}}\left(\mathrm{X}_{E E Z_{i}}, \mathrm{E}_{E E Z_{i}}\right)+H_{H S_{i}}\left(\mathrm{X}_{H S}, \mathrm{E}_{H S_{i}}\right)\right)-C_{i}\left(E_{E E Z_{i}}, E_{H S_{i}}\right)
$$

where the first term captures revenues with $p$ the (constant) fish price and $H_{E E Z_{i}}$ and $H_{H S_{i}}$ the harvest levels obtained by nation $i, i=1, \ldots, N$, from fishing in its own EEZ and in the high seas, and the second term represents the cost function which depends on inputs, i.e., efforts. Each player $i$ has to make two strategic choices: the fishing effort in his/her own EEZ, $E_{E E Z_{i}}$ and the fishing effort in the high seas, $E_{H S_{i}}$.

Cooperation among a group of players corresponds to the establishment of an RFMO with the purpose of managing and conserving the fish stocks jointly. If RFMOs are established, they are single agreements, i.e., no RFMOs co-exist that regulate the same fish stock. Participation in an RFMO is voluntary and open to all states as reflected by Article 8(3) of the UN Fish Stocks Agreement in 1995. Moreover, we assume that states, which decide against membership in an RFMO, cannot be prevented from harvesting in the high seas. ${ }^{16}$

In order to capture these institutional features, we choose from the set of coalition formation games the single coalition open membership game due to d'Aspremont et al. (1983) which has been frequently applied in the literature on IEAs (e.g., Finus and Caparrós, 2015 for an overview) but also in other areas of economic interest (e.g., Bloch, 2003 and Yi, 1997 for surveys). This coalition game is a two-stage game.

In the first stage, players decide upon their membership. Those players that join the RFMO form the coalition and are called members, those that do not join are called non-members. The decisions in the first stage lead to a coalition structure $\{S, 1, \ldots, 1\}$ where $S$ is the set of coalition members and the remaining players are singletons. Given the simple structure of the first stage, a coalition structure is fully characterized by coalition $S$. In the second stage, players choose their economic strategies, which are fishing efforts in our model. In each stage, strategies (participation and fishing effort) form a Nash equilibrium. The game is solved backward.

In the second stage, given some coalition $S$ has formed in the first stage, non-members act non-cooperatively and maximize their individual payoff, $\Pi_{i}$, while members, acting cooperatively, maximize the aggregate payoff of their coalition,

$$
\begin{aligned}
\Pi_{S}= & \sum_{i \in S} \Pi_{i}: 17 \\
& \underset{\left(E_{E E Z_{j}}, E_{H S_{j}}\right)}{\arg \max } \Pi_{j}(E) \quad \forall j \notin S \\
& \underset{\left(E_{E E Z_{S}}, E_{H S_{S}}\right)}{\arg \max } \Pi_{S}(E)
\end{aligned}
$$

where $E=\left(E_{E E Z_{1}}, \ldots, E_{E E Z_{N}}, E_{H S_{1}}, \ldots, E_{H S_{N}}\right)$ denotes the vector of all fishing efforts whereas $E_{E E Z_{S}}=\left(E_{E E Z_{i}}\right)_{i \in S}$ and $E_{H S_{S}}=$ $\left(E_{H S_{i}}\right)_{i \in S}$ denote the vectors of fishing efforts of the coalition members in the EEZs and in the high seas, respectively. It is important to note that within an RFMO, only the member who owns an EEZ fishes in this EEZ, but fishing efforts in EEZs are coordinated across RFMO members. In the high seas, each member fishes and members coordinate their efforts. Coordination means that members are aware of the externalities among each other. That is, ceteris paribus, fishing reduces the stock, which for the same effort reduces harvest and/or increases the cost of fishing. Moreover, fishing in zone $i$ will either reduce the outgoing diffusion to other zones or will increase incoming diffusion from other zones, depending on the net direction of diffusion if migration depends on stock densities. Similarly, in a sink-source model, fishing in the source will reduce migration to the sink.

The simultaneous maximization of (4) and (5) delivers the equilibrium fishing efforts $E^{*}(S)$. As noted above already, this equilibrium is identical to the Nash equilibrium known from models without coalition formation if coalition $S$ comprises only a single player, $S=\{i\}$, or is empty $S=\emptyset$. Moreover, if coalition $S$ comprises all players, $S=\{1, \ldots, N\}$, i.e., the grand coalition forms, the equilibrium corresponds to the socially optimal fishing vector. Hence, the entire range from no cooperation, partial cooperation to full cooperation can be captured by this approach.

It is worthwhile to mention that the solution to (4) and (5) will be identical for every coalition $S \subseteq\{1, \ldots, N\}$, i.e., the degree of cooperation does not matter, if and only if both $\alpha=0$ (no high seas) and there is no diffusion. That is, there is no externality across players and hence the study of RFMOs is not interesting. This would correspond to a system of closed patches with no high seas. In contrast, even if there is no diffusion between any zone, as long as $\alpha>0$, there is an area of common property resource that can be exploited by all countries. (This would be a system of closed patches with high seas.) Thus, no, partial and full cooperation imply different vectors of equilibrium fishing efforts. This is also true even if $\alpha=0$, i.e.,

\footnotetext{
16 The legal basis and the implications of giving up this assumption are briefly discussed in Section 8.1.

17 The assumption that RFMO-members choose their fishing efforts cooperatively, both in the high seas and in their EEZs, is in line with FAO (2010), p. 123, which states: "Each RFMO is, inter alia, called upon to ensure that the management measures for the high seas segments of the resources and those measures for the intra-EEZ segments of the resources are compatible with each other".
} 
Table 2

Functional Specification of Model.

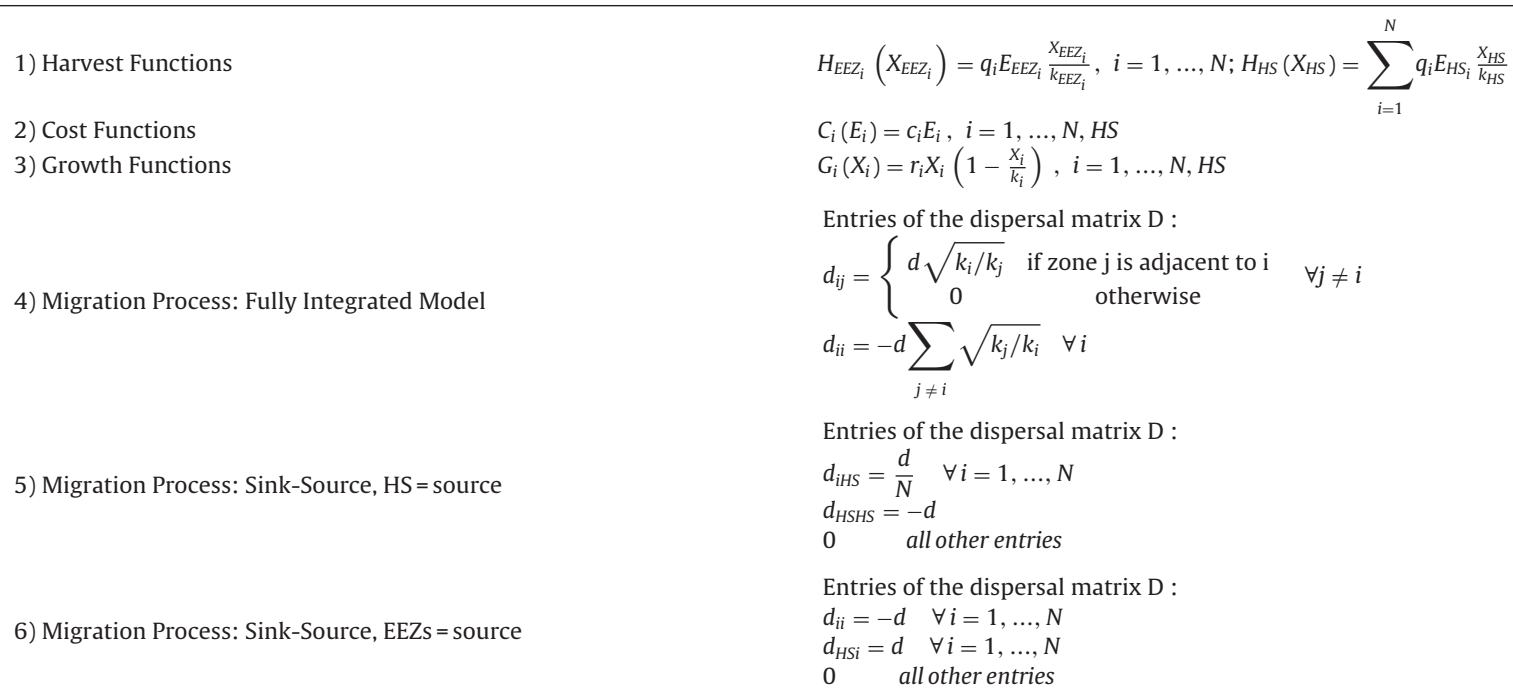

$r_{i}=$ intrinsic growth rate in region $i ; X_{E E Z_{i}}, X_{H S}=$ stock in $E E Z_{i}$ and $H S$, respectively; $k_{E E Z_{i}}, k_{H S}=$ carrying capacity in $E E Z$ and $H S$, respectively; $q_{i}=$ efficiency parameter of country $i ; E_{E E Z_{i}}, E_{H S_{i}}=$ efforts in $E E Z_{i}$ and $H S$, respectively; $d_{i j}=$ diffusion parameter between region $i$ and $j ; c_{i}=$ cost parameter of country $i$.

all property is privately owned, as long as there is diffusion among at least two zones such that the action of one player has an impact on at least one other player. Hence, not only in a fully integrated model but also in sink-source model, equilibrium efforts will differ with the degree of cooperation.

Equilibrium efforts $E^{*}(S)$ derived from (4) and (5) together with the steady-state conditions of stocks in (2) have to be inserted into the payoff function (3) to determine individual payoffs $\Pi_{j \notin S}^{*}(S)$ and the coalitional payoff $\Pi_{S}^{*}(S)$. The coalitional payoff will have to be distributed in some way such that $\sum_{i \in S} \Pi_{i}^{*}(S)=\Pi_{S}^{*}(S)$. For details see Section 4.

Having determined equilibrium payoffs for every possible coalition structure in the second stage, we can now proceed to the first stage. In the first stage, a coalition $S$ is considered to be stable if it satisfies the following two conditions:

\section{Internal stability}

No member $i \in S$ finds it profitable to deviate, i.e., the gain from leaving the coalition is non-positive: $\Pi_{i}^{*}(S\{i\})-\Pi_{i}^{*}(S) \leq$ $0, \forall i \in S$.

\section{External stability}

No non-member $j \notin S$ finds it profitable to join the coalition, i.e., the gain from joining the coalition is non-positive: $\Pi_{j}^{*}(S \cup\{j\})-\Pi_{j}^{*}(S) \leq 0, \forall j \notin S$.

Note that the grand coalition is externally stable by definition, as there is no outsider left that could join the coalition.

\section{Model specification and solution procedure}

\subsection{Preliminaries}

As mentioned above, the model is solved by backward induction. The most complex part relates to the second stage in which optimal fishing efforts have to be determined for a given coalition structure. For this, the system of Eq. (2), which represents the steady-state conditions, and the first-order conditions derived from (4) and (5) have to be solved simultaneously in order to obtain steady-state stocks and equilibrium fishing efforts. The solution to the $3 N+1$ equations will depend on the specification of the functional relationship between stocks, efforts and payoffs. That is, we have to specify growth, harvest and cost functions and define a diffusion matrix, which describes the migration process. This is done in Section 4.2 . Moreover, as we face a highly nonlinear system of equations, which, generally, cannot be solved analytically, we have to rely on numerical simulations, which we describe in Section 4.3.

\subsection{Functional specification}

In this section, we specify the functional relationships (see Table 2). It will be apparent that the specifications follow the mainstream assumptions in the literature.

Regarding the harvest function (Table 2, first row), we have to bear in mind that except for the extension which we consider in Section 8.1, all countries are allowed to fish in the high seas whereas only the owner of an EEZ is allowed to fish in this territory. Hence, the harvest in the high seas is the sum of the individual harvest levels of each country. As commonly 
assumed, (total) harvest depends linearly on (total) fishing efforts and stock densities, with $q_{i}$ denoting the catchability coefficient, a measure of the efficiency of fishing fleet $i$. Hence, for the same effort, countries will harvest more if the stock density is high (stock divided by carrying capacity).

It is a common assumption in the literature on fishery management (Gordon, 1954; Pezzey et al., 2000 and Sanchirico and Wilen, 1999) that costs (Table 2, second row) depend linearly on extraction efforts, though they are strictly convex if expressed in terms of harvest levels, where $c_{i}$ is the (constant) marginal cost of fishing effort of the fishing fleet of country $i$.

The most commonly used growth function (Table 2, third row) is of the logistic type where $r_{i}$ denotes the intrinsic growth rate in zone $i$, which is our measure of rivalry with the degree of rivalry inversely related to the value of $r_{i}$. We follow Hannesson (1998); Kvamsdal and Sandal (2008) and many others and assume that growth depends on the local characteristics of a zone. Hence, even if the growth rate $r_{i}$ is the same in every zone, growth may differ across zones because stocks $X_{i}$ and stock densities $X_{i} / k_{i}$ may be different. Moreover, note that growth cannot generally be aggregated across zones. See Appendix 3 in the Supplementary material for details.

Three aspects need to be considered when specifying the migration process.

Firstly, the arrangement of zones has to be specified. We choose an intuitive and symmetric arrangement of the $N+1$ zones: the EEZs are arranged in a circle with the high seas at its center, as depicted in Fig. 1. This avoids boundary effects that would emerge with a linear arrangement and represents a good first-order approximation for the geographical setting of many examples where an area of high seas is surrounded by coastal zones. A good match of this assumption is for instance the 'Banana Hole' in the Northeast Atlantic or the 'Donut Hole' in the Bering Sea (see Meltzer, 1994).

Secondly, we have to determine the direction of migration. (See Sanchirico and Wilen, 1999 for a general discussion.) Fig. $1 \mathrm{a}$ represents our base case, Fig. $1 \mathrm{~b}$ and $\mathrm{c}$ constitute extensions. In Fig. 1a, we assume that diffusion is possible between all adjacent zones and in all directions. This corresponds to the fully integrated model if diffusion takes place between all zones and approaches the closed patch model if diffusion is zero. In Fig. 1b and 1c we consider uni-directional diffusion, in line with what is called a sink-source model. In Fig. 1b, the high seas is the source and the EEZs are the sinks. There is no diffusion between EEZs. In Fig. 1c, this is reversed. The EEZs are the source and the high seas is the sink. Again, no diffusion is assumed between EEZs.

Thirdly, the intensity of migration between two neighboring fishing grounds needs to be specified (Table 2, fourth, fifth and sixth row).

For the fully integrated model in Fig. 1a, we assume a density-dependent diffusion process, i.e., the strength of migration between neighbouring fishing grounds depends on the difference in stock densities (e.g., Armstrong and Skonhoft, 2006 and Sanchirico and Wilen, 1999, 2005). That is, the change of stock $X_{i}$ due to diffusion between zone $i$ and $j$ over time is given by

$$
\left(\frac{\partial X_{i}}{\partial t}\right)_{i \leftrightarrow j}=\gamma(i, j)\left(\frac{X_{j}}{k_{j}}-\frac{X_{i}}{k_{i}}\right) \text {. }
$$

If the stock density in zone $j$ is larger (smaller) than in zone $i$, this term is positive (negative) and there is incoming (outgoing) diffusion in zone $i$. By symmetry, we have:

$$
\left(\frac{\partial X_{i}}{\partial t}\right)_{i \leftrightarrow j}=\left(-\frac{\partial X_{j}}{\partial t}\right)_{i \leftrightarrow j} .
$$

The parameter $\gamma(i, j)$ may be uniform across zones or may reflect the characteristics of adjacent zones. We choose $\gamma(i, j)=$ $d \sqrt{k_{i} k_{j}}$. That is, diffusion between larger zones is larger than between smaller zones. This means we use the geometric mean of the carrying capacities, $\sqrt{k_{i} k_{j}}$, as a scaling factor. This seems to be more appropriate than say the arithmetic mean, $\left(k_{i}+k_{j}\right) / 2$, which would imply significant diffusion even if one carrying capacity is very small (i.e., $k_{i} \rightarrow 0$ or $k_{j} \rightarrow 0$ ). The general intensity of migration, as a characteristic of a particular species is captured by the diffusion parameter $d$. This parameter determines the general degree of technical non-excludability. For highly migratory species, parameter $d$ would be very large. The details of how diffusion is captured by the diffusion matrix in Fig. 1a are described in Appendix 2 in the Supplementary material.

Taken together, $\gamma(i, j)$ determines the speed at which stock densities are balanced in a given time span. Note that in a steady-state, there can be net diffusion if equilibrium stock densities in neighboring areas are different. Moreover, the diffusion parameter $d$ can exceed the growth rate $r$ without resulting in negative stocks because the absolute rate of diffusion in the steady-state depends not only on $d$ but also on the difference in densities, which will be small when $d$ is high. ${ }^{18}$ The density-dependent model is typically motivated by the observation that fish move from higher to lower densities as there is less competition for food. It is also in line with random movements, which are also known as Brownian motion.

The details of the sink-source models as displayed in Fig. 1b and c are provided in Appendix 1 in the Supplementary material. Sink-source models are considered to be a good fit for fish species with a particular migratory pattern which

\footnotetext{
${ }^{18}$ For instance, think of a very low value of $r$ (e.g., whales). In this case, it may happen that parameter $d$ is larger than $r$, such that differences in regional harvesting $(H)$ are balanced by dispersal $(D)$, rather than by growth $(G)$, maintaining the steady-state given by $G-H+D=0$. For such a highly migratory, slow-growing species, a stock that is heavily exploited in one region would be replenished by incoming diffusion from other regions rather than intrinsic growth.
} 


\section{a) Fully Integrated Model}

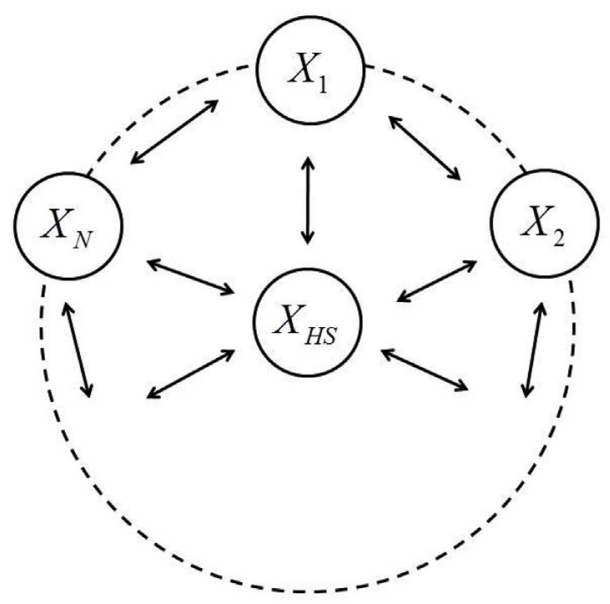

* Arrows indicate potential dispersal.

c) Sink-Source Model: EEZs Source

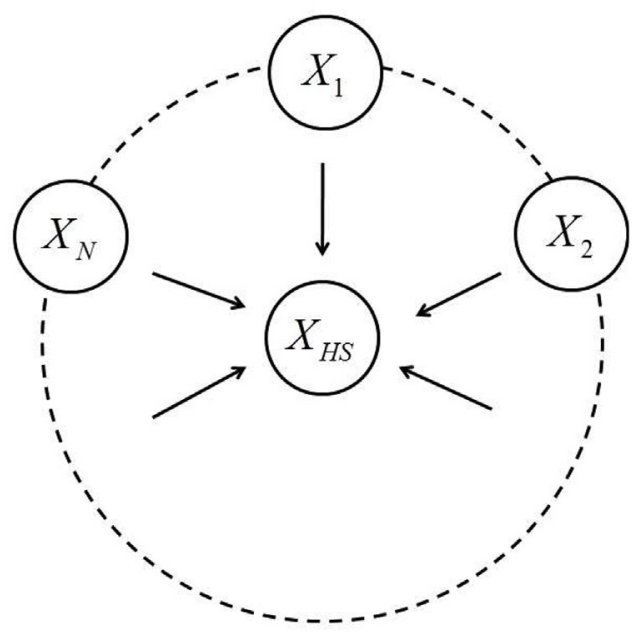

b) Sink-Source Model: High Seas Source

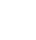


Table 3

Parameter Values in Simulations*.

\begin{tabular}{llll}
\hline Simulation Runs & $c$ & $r$ & $d$ \\
\hline A & 0.5 & 0.5 & $\mathbf{0}-\mathbf{1 . 2 8}$ \\
B & $\mathbf{0 . 2 5}-\mathbf{0 . 7 5}$ & 0.5 & $\mathbf{0}-\mathbf{1 . 0}$ \\
C & 0.5 & $\mathbf{0 . 2 5}-\mathbf{0 . 7 5}$ & $\mathbf{0}-\mathbf{1 . 0}$ \\
\hline
\end{tabular}

* Parameter variations for simulation runs are indicated in bold; $p=1, q=1$ and $k_{\text {tot }}=4$ are assumed throughout.

idea to capture various degrees of socially constructed and technical excludability. Only for extreme parameter values can analytical solutions be obtained.

For instance, if we let $\alpha=1$, then this is the model with high seas only, and results follow from Pintassilgo and Lindroos (2008) for symmetric players and from Lindroos (2008) and Pintassilgo et al. (2010) for asymmetric cost functions. Note that in our model diffusion does not matter for $\alpha=1$ because diffusion is measured between and not within a zone.

By the same token, we can conjecture that if we let diffusion parameter $d$ go to infinity, then the value of $\alpha$ does not matter. Essentially, the allocation of property rights becomes irrelevant because very fast diffusion effectively links them to one zone. De facto, this corresponds to the situation "only high seas" with $\alpha=1$ as mentioned above.

Finally, if $\alpha=0$ and all $d=0$, there is no externality. Hence, second stage fishing efforts are socially optimal regardless of which coalition forms. Consequently, there is no gain from cooperation but also no incentive to free-ride and hence the grand coalition is stable as we argue in Result 4, Section 6, below.

Taken together, new interesting results can only be obtained in the interior of the allocation and diffusion parameter space for which simulations are required.

It is evident that computing time and capacity requirements increase exponentially with the number of players. For this reason, we confine ourselves to the case of $N=3$ players. This is certainly the minimum number of players in order to make the analysis of coalition formation interesting, but as it turns out, this is sufficient to derive interesting qualitative results. ${ }^{19}$ For $N=3$, we have to consider three possible coalition structures, namely the grand coalition, the two-player coalitions and the all-singletons coalition structure. Furthermore, we will restrict the analysis to symmetric parameter values for all players (and therefore we can drop the index for parameters $q_{i}, c_{i}$, and $r_{i}$ henceforth). This implies symmetric equilibria in the Nash equilibrium and the social optimum. Moreover, all possible two-player coalitions are equivalent with symmetric payoffs for coalition members (i.e., equal split of the total coalitional payoff), though they differ from the payoff of a non-member. ${ }^{20}$ Moreover, with symmetry, internal and external stability are closely related (Carraro and Siniscalco, 1993): if a coalition with $n$ players is not internally stable, then the coalition with $n-1$ players is externally stable.

Simulations require the assumption of numerical values for the parameters of the model. Fortunately, a closer look at the system of equations reveals that results will depend on only few parameters. The choice of parameter values follows good practice, covering (almost) the entire parameter space (under the assumption of interior solutions) as summarized in Table 3.

First note that the total carrying capacity $k_{\text {tot }}$ just represents a scaling factor which we normalize to 4 as there are four zones. ${ }^{21}$ Moreover, all subsequent results do not depend on $c, p$ and $q$ independently but just on their ratio $\frac{c}{p q}$, with $\frac{c}{p q k_{\text {tot }}}$ being commonly referred to as the 'inverse efficiency parameter' (see Mesterton-Gibbons, 1993). Thus, we normalize $p$ and $q$ to 1 and hence only vary $c$, resulting, ceteris paribus, in a variation of the relation $c / p q$. Since in this setting prohibitive costs at which countries quit fishing are given by $c \geq 1$ irrespective of scenario of cooperation, we need to assume $c \in[0,1]$ for interior solutions. In our simulations, we set the base case value to $c=0.5$ and consider two other values: $c=0.25$ and $c=0.75$. For the intrinsic growth rate $r$, we choose the commonly used base value $r=0.5$ and consider two other values: $r=0.25$ and $r=0.75 .^{22}$ Recall, the growth rate approximates the degree of rivalry.

For the diffusion parameter our simulations cover the range $d \in\left[0, d_{\max }\right]$ in intervals of $\Delta d=0.08$ with the upper bound $d_{\max }=1.28$ that approximates well the limit $d \rightarrow \infty .^{23,24}$ With respect to $\alpha$, we cover the whole range $\alpha \in[0,1]$,

\footnotetext{
19 This assumption has also the advantage that the density-dependent model is a fully integrated system. Strictly speaking, a fully integrated system, in which all zones are linked, does not exist if the number of zones exceeds four (due to the four color map theorem).

20 Thus, players are ex-ante symmetric (before coalition formation) but may be ex-post asymmetric, depending on whether they become members or non-members. The assumption of ex-ante symmetric players is widespread in the literature on coalition formation, not only on international environmental treaties but also in the context of other economic problems (see, e.g., Bloch, 2003 and Yi, 1997 for an overview).

21 This is in line with the common normalization $k=1$ in papers that deal with only a single zone (e.g., Pezzey et al., 2000). In our model, assuming no diffusion between zones with $k_{\text {tot }}=4$ and setting $\alpha=0.25$ results in four isolated zones with carrying capacities $k_{i}=1$. See Eq. ( 1 ).

22 Our base case values $c=0.5$ and $r=0.5$ are commonly assumed in the literature (e.g., Hannesson, 1997 and Tarui et al., 2008 ). Note that a variation of the growth rate in the range $0.25 \leq r \leq 0.75$ (e.g., as considered in Nøstbakken, 2006) already has a significant impact on the outcome in terms of payoffs. For instance, in models with only a single zone (e.g., Pezzey et al., 2000), which correspond to $\alpha=1$ in our model, aggregate payoffs in the Nash equilibrium at a growth rate $r=2 / 3$ are already as high as in the social optimum at $r=0.5$.

${ }^{23}$ Results for $d=d_{\max }$ differ less than $5 \%$ from the results in the limit $d \rightarrow \infty$ and converge towards the 'only high seas' scenario ( $\alpha=1$ ), which can be calculated analytically as pointed out above.

${ }^{24}$ For the density-dependent diffusion model, $d>>r$ is possible since diffusion will always cease as soon as differences in stock densities are balanced. In contrast, in our extensions, which considers a sink-source model, $d<r$ must hold to ensure that a steady-state exists in which intrinsic growth can balance outgoing diffusion and harvest.
} 
with $\alpha=0$ implying that the entire fishing area comprises only state-owned exclusive economic zones and $\alpha=1 \mathrm{implying}$ that the entire area comprises only the common property high seas. ${ }^{25}$ All results are tested in the entire interval in steps of $\Delta \alpha=0.05$. Note that the carrying capacities, $k_{E E Z}$ and $k_{H S}$, follow from the allocation parameter $\alpha$ and the total carrying capacity is given by $k_{t o t}=4$ (see Section 3.2, Eq. (1)).

By varying the allocation parameter $\alpha$ and the diffusion parameter $d$, we model different degrees of socially constructed and technical excludability, respectively, as shown in Table 1. At the same time, we are able to capture all four categories of shared fish stocks as highlighted in footnote 7: transboundary stocks ( $\alpha=0$ and $d>0)$, straddling stocks and highly migratory fish stocks $(0<\alpha<1$ and $d>0)$ and discrete high seas stocks $(\alpha=1)$. We also capture the "boundary cases" of non-shared stocks ( $\alpha=0$ and $d=0$ ), i.e., stationary stocks within EEZs, and the case in which the EEZ boundaries become irrelevant $(d \rightarrow \infty)$. In our extension to a sink-source model with $0<\alpha<1, d>0$, and $d<r$, we can additionally capture uni-directional migration patterns.

Through the variation of a single parameter in a comparative static way, we can analyze how such a (ceteris paribus) variation affects outcomes. However, in reality, when comparing for instance different fisheries, they will usually differ in more than one parameter. Hence, interpretations require some caution. For instance, increasing the economic parameter $c$ means that fishing becomes more costly, and hence everything else equal, will lead to lower efforts, lower harvest levels and higher stocks. Increasing the growth rate $r$ implies a faster reproduction rate, which will lead to lower or higher equilibrium stocks in equilibrium, depending on how fishing efforts are adjusted (see Result 3 ).

Importantly, parameter $\alpha$ is an institutional/legal parameter defining fishing rights. At the same time, it defines the relative size of habitats, with possible different stock densities in the various zones. The question arises, whether it is the characteristics of the biological model that determine the impact of $\alpha$ on outcomes (e.g., equilibrium stock levels) or rather the change in the legal status associated with a variation of $\alpha$. We argue that, in the density-dependent model with symmetric parameter values, a variation of $\alpha$ does not affect the biology of the system as such, and, hence, changes in stock levels are entirely the result of a change of the legal status.

To see this, consider an enlargement of EEZs as implemented by the 1982 UNCLOS (corresponding to a decrease in $\alpha$ ). Assuming that stock densities were different in the high seas and the EEZ areas before the change, then there will be a transition phase during which an enlarged EEZ will exhibit a spatially inhomogeneous distribution of stock. Aggregation of such an inhomogeneous distribution into one single stock parameter $X_{i}$ would not be feasible, due to the non-linearity of the growth function (see Appendix 3 in the Supplementary material for details). Yet, our model is not intended to cover such a transition phase. In a new steady state, however, efforts and thereby the stock within one zone will be distributed homogeneously again. Hence, in the ex-post equilibrium, it is the economic implication (i.e., change in fishing efforts) of the change in the legal status that changes outcomes, and not changes of the biology. For instance, let $d=0$ and consider the extreme cases $\alpha=0$ and $\alpha=1$. Non-cooperative equilibrium stock levels will be lower for $\alpha=1$ than for $\alpha=0$, not because stock disappears but because no territory is publicly available for $\alpha=0$ and all territory is available for $\alpha=1$. The same is true in a partially cooperative equilibrium. In contrast, in the social optimum, $\alpha$ will not matter for total stocks. This will be apparent from Result 1 below.

All our simulation runs are conducted with the software package Maple 18 with a 10 digit precision. For each parameter combination, we let Maple numerically solve the system of equations five times, each time with different starting values for the variables stocks and efforts, uniformly distributed within the range of possible values. For stocks, this range is obviously given by $\left[0, k_{E E Z}\right]$ and $\left[0, k_{H S}\right]$, respectively. For efforts, the range is $\left[0, E_{\max }\right]$. For instance, the upper limit in the fully integrated model is given by $E_{\max }=\left[\frac{p q-c}{p^{2} q^{2}}\right] \frac{r k \text { tot }}{3}$, which can be calculated analytically and corresponds to the effort of a nonmember if a coalition of two players has formed and there are no EEZs, i.e., $\alpha=1$. We did not observe any dependency on starting values. Moreover, solutions converge to analytical results for the extreme parameter values discussed above. Finally, equilibrium values change smoothly with a change of parameter values; no jumps in equilibrium values have been observed. Taken together, although we are not able to give a formal proof of uniqueness, we have several heuristic indications that multiple equilibria do not arise in this model. This gives us confidence that Maple correctly determines the unique interior equilibrium in our simulation runs.

\subsection{Qualifications}

While our model is based on the most common assumptions in international fisheries (see, e.g., Stavins, 2011), we are well aware that some aspects remain neglected (see, e.g., Clark, 2010). With respect to resource characteristics, we do not deal with the age structure of the stock, possible predator-prey relations requiring a multi-species approach, or migratory patterns which are related to the life-cycle of a species. We also do not model the micro level of fishery policies and production, mainly related to the national implementation of cooperative or non-cooperative fishery policies and the production function of individual fishermen. Thus, we neglect issues like setup or fixed costs, policy regulations like gear restrictions or allocation of tradable or non-tradable fishing quotas to individual fishermen, efforts to reduce by-catch, and port state measures

\footnotetext{
${ }^{25}$ The way we have set up our sink-source model, neither $\alpha=0$ nor $\alpha=1$ makes sense. Thus, $\alpha \in[0.05,0.95]$ in the sink-source model to ensure the existence of both, sink and source.
} 
to deter illegal, unregulated and unreported fishing. Essentially, national implementation is assumed to be efficient and perfectly enforceable in our setting. We also ignore transaction costs of implementing and administrating RFMOs as for instance considered in McCarthy et al (2001) and for common pool resources in general, in Ostrom (1990). Hence, as a tendency, our model overestimates the possibilities of cooperation. Concerning international fisheries management, our crucial assumption is that all countries fish in their own EEZ and the high seas. This abstracts from the fact that some coastal states are not engaged in high seas fishing and that distant water fishing states might operate in high seas areas not adjacent to their coastal waters. It also means that coastal states do not sell their fishing rights to other states (access agreements). In line with Art. 87, UNCLOS 1982, we assume that non-RFMO members cannot be deterred from fishing in the high seas, covering an alternative scenario where exclusion is possible in a brief discussion in Section 8.1. Finally, regarding the sinksource model, there remain some unsolved issues with respect to the aggregation of zones as explained in Appendix 3 in the Supplementary material.

\section{Results: second stage of coalition formation}

In this section, we analyze how equilibrium fishing efforts, stocks and payoffs depend on the degree of cooperation and the crucial parameters of our model. This will provide useful information for the interpretation of the incentive structure to form stable coalitions as analyzed in the first stage of coalition formation in Section 6. We focus on the fully integrated model with density-dependent diffusion, and treat the sink-source model as an extension in Section 8.2. As mentioned above, the system of first order conditions is a system of non-linear equations, which cannot be solved analytically. Nevertheless, it is instructive to consider selective first order conditions in general form. Suppose country $i$ behaves non-cooperatively. Then the first order condition in terms of effort levels in the high seas of country $i$ is given by:

$$
\begin{gathered}
\frac{\partial \Pi_{i}}{\partial E_{H S_{i}}}=\frac{\partial\left[p\left(H_{H S_{i}}(X, E)+H_{E E Z_{i}}(X, E)\right)-C\left(E_{E E Z_{i}}+E_{H S_{i}}\right)\right]}{\partial E_{H S_{i}}}=0 . \\
\text { Using } H_{H S_{i}}=q E_{H S_{i}} X_{H S} / k_{H S}, H_{E E Z_{i}}=q E_{E E Z_{i}} X_{E E Z_{i}} / k_{E E Z_{i}} \text {, and } C\left(E_{E E Z_{i}}+E_{H S_{i}}\right)=c\left(E_{E E Z_{i}}+E_{H S_{i}}\right) \text {, we have: }
\end{gathered}
$$

(i)

$$
p q\left[\frac{X_{H S}}{k_{H S}}+\frac{E_{H S_{i}}}{k_{H S}} \frac{\partial X_{H S}}{\partial E_{H S_{i}}}+\frac{E_{E E Z_{i}}}{k_{E E Z_{i}}} \frac{\partial X_{E E Z_{i}}}{\partial E_{H S_{i}}}\right]-c=0
$$

Thus, a marginal increase of player i' s effort in the high seas, implies:

i a marginal increase in player $i$ ' s harvest level from the high seas (first term);

ii a marginal decrease in the stock level in the high seas (second term);

iii a marginal decrease in the adjacent stock level in player i' s EEZ via diffusion (third term) and iv a marginal increase in the cost (fourth term).

In the presence of diffusion, player $i$ chooses a fishing effort in the high seas, which balances the positive impacts (i) and the negative impacts (ii), (iii) and (iv). For the specific functions, impact (i) and (ii) will depend on the size of the high seas, $k_{H S}$, and impact (iii) on the size of the exclusive economic zone of player $i, k_{E E Z_{i}}$ and hence all three impacts depend on parameter $\alpha$. For impact (ii), the negative value on the stock in the high seas ${ }^{\partial X_{H S} / \partial E_{H S}}$ will also depend on the growth rate $r$. For impact (iii) the negative value on the stock in player $i$ ' s EEZ $\partial x_{E E Z_{i}} \partial E_{H S}$, will depend on the intensity of diffusion and hence on parameter $d$. The impact is always negative because fishing in the high seas either reduces incoming diffusion into player $i$ 's EEZ, or increases the outgoing diffusion from this EEZ to the high seas, depending on the equilibrium stock levels in the different zones. Note that the FOC captures only the impact of efforts on own payoffs; externalities imposed on other players are not internalized as long as there is no cooperation.

To make things even more complicated, we note that player $i$ also has a first order condition for his effort in his EEZ, taking care of diffusion between the high seas and his EEZ. Moreover, the first order conditions of a coalition would show additional marginal effects across members' EEZs and those EEZs and the high seas as coalition members behave cooperatively by maximizing aggregate payoffs.

For notational convenience, we skip in the following the term "equilibrium". Unless otherwise stated, we always refer to efforts, stocks and payoffs in the respective equilibrium: no, partial and full cooperation, i.e., all singleton coalition structure, two-player coalition and grand coalition with three players. We may recall that the degree of socially constructed (technical) excludability, measured by the allocation parameter $\alpha$ (diffusion parameter $d$ ), is inversely related to the value of this parameter. The same holds for the degree of rivalry measured by the intrinsic growth parameter $r$.

\section{Result 1: the role of socially constructed and technical excludability}

Under full cooperation, the total fishing effort, total stock and total payoff are independent of the degree of socially constructed excludability (allocation parameter $\alpha$ ) and the degree of technical excludability (diffusion parameter $d$ ) where totals refer to 
aggregation over all players and zones. Under no and partial cooperation, the total fishing efforts over all players increase in the parameter $\alpha$ and the diffusion parameter d. Accordingly, the total stock in the entire fishing area and the total payoff over all players decreases in $\alpha$ and $d$.

In the social optimum, neither the distinction between high seas and EEZs matters for equilibrium strategies nor the level of diffusion. This is because in the social optimum externalities across all players are fully internalized, i.e., the social planner maximizes the aggregate payoff over all players and zones. Efforts are distributed such that effort densities, i.e., the efforts per area $E_{E E Z, i} / k_{E E Z}$ and $E_{H S, \text { tot }} / k_{H S}$ are equal everywhere, irrespective of $d$ and $\alpha$. Accordingly, stock densities $X_{E E Z, i} / k_{E E Z}$ and $X_{H S} / k_{H S}$ are the same in every zone and independent of $d$ and $\alpha{ }^{26}$ This substantiates our claim above that for the density-dependent model $\alpha$ does not affect the biology of the system as such. This is also true for no and partial cooperation, though a change of $\alpha$ changes property rights and hence equilibrium fishing efforts.

Under no and partial cooperation, a high value of $\alpha$, i.e., a low degree of socially constructed excludability, aggravates over-exploitation and leads to higher efforts, which is reflected in lower stocks and payoffs. Similarly, the higher the diffusion between zones, i.e., the lower the degree of technical excludability, the more will the fish stock be exploited (high fishing efforts), resulting in low stocks. This translates into low individual payoffs and a low total payoff. For the total effort and total payoff under no cooperation this is illustrated in Fig. 2, with similar graphs for partial cooperation. ${ }^{27}$

The next result measures the importance of cooperation as a function of our model parameters. We consider relative normalized differences (as absolute values have no sensible meaning in a stylized model) related to the benchmark full cooperation.

Result 2: total stocks and payoffs under different degrees of cooperation

Let the total fish stock in the entire area and the total payoff over all players under full, no and partial cooperation be denoted by $X^{F}, X^{N}$, and $X^{P}$, and $\Pi^{F}, \Pi^{N}$ and $\Pi^{P}$, respectively, then

a) $\frac{X^{P}-X^{N}}{X^{F}}$ and $\frac{X^{F}-X^{N}}{X^{F}}$ increase in $\alpha$ and $d$;

b) $\frac{\Pi^{P}-\Pi^{N}}{\Pi^{F}}$ and $\frac{\Pi^{F}-\Pi^{N}}{\Pi^{F}}$ increase in $\alpha$ and $d$.

Result 2 stresses that the relative importance of cooperation, either partial or full, increases with the degree of interconnectedness between players, in line with Sampson and Sanchirico (2019). That is, the importance increases the lower the degree of socially constructed and technical excludability, i.e., the higher the spatial allocation parameter $\alpha$ and the higher the diffusion parameter $d$ are. In other words, if $\alpha$ and/or $d$ are high, we would hope that full cooperation or at least partial cooperation is stable which is tested in Section 6. In contrast for low values, cooperation does not matter much.

The next result looks at the effect of a variation of the cost parameter $c$, reflecting the unit production cost of fishing, and the growth parameter $r$, our indicator of the degree of rivalry, reflecting how fast the stock recovers from fishing.

\section{Result 3: the role of the cost and growth parameter under different degrees of cooperation}

a) Total equilibrium efforts and payoffs decrease while stocks increase in the cost parameter $c$. This holds irrespective of the allocation parameter $\alpha$, the diffusion parameter $d$, and the degree of cooperation. $\frac{X^{P}-X^{N}}{X^{F}}$ and $\frac{X^{F}-X^{N}}{X^{F}}$ as well as $\frac{\Pi^{P}-\Pi^{N}}{\Pi^{F}}$ and $\frac{\Pi^{F}-\Pi^{N}}{\Pi^{F}}$ decrease in $c$ whenever there is diffusion.

b) Total equilibrium efforts and payoffs increase in the growth parameter $r$. This holds irrespective of the allocation parameter $\alpha$, the diffusion parameter $d$, and the degree of cooperation. Under full cooperation, equilibrium stocks are independent of $r$. Under no and partial cooperation the total stock increases in $r$ whenever there is diffusion. $\frac{X^{P}-X^{N}}{X^{F}}$ and $\frac{X^{F}-X^{N}}{X^{F}}$ as well as $\frac{\Pi^{P}-\Pi^{N}}{\Pi^{F}}$ and $\frac{\Pi^{F}-\Pi^{N}}{\Pi^{F}}$ decrease in $r$ whenever there is diffusion.

The intuition of Result 3a is straightforward. With increasing unit production costs, equilibrium fishing efforts are reduced, resulting in lower payoffs, though higher fish stocks. Thus from an ecological point of view, higher production costs help to preserve fish stocks but from an economic point of view it reduces economic rents. Shrinking rents under all scenarios of cooperation with increasing costs also implies that the relative differences in total payoffs between the two cooperative

\footnotetext{
26 Obviously, this result rests on the assumption of symmetric parameters and in particular symmetric dispersal patterns. For asymmetry, an optimal fishing policy, i.e., the allocation of efforts, as well as resulting stock densities depend on the characteristics of fishing grounds and dispersal patterns (cf. Costello and Polasky, 2008).

27 With respect to Fig. 2 note that similar graphs are obtained for other combinations of the parameter values of $c$ and $r$. Those combinations follow from Table 3. Hence, there a six c-r-parameter constellations considered in the simulations under no cooperation and the same is true for partial cooperation, which give rise to Result 1. Consequently, given the number of subsequent results, it is evident that we cannot display all simulation results in graphs. However, all graphs are available upon request from the authors.
} 
a) Total Effort

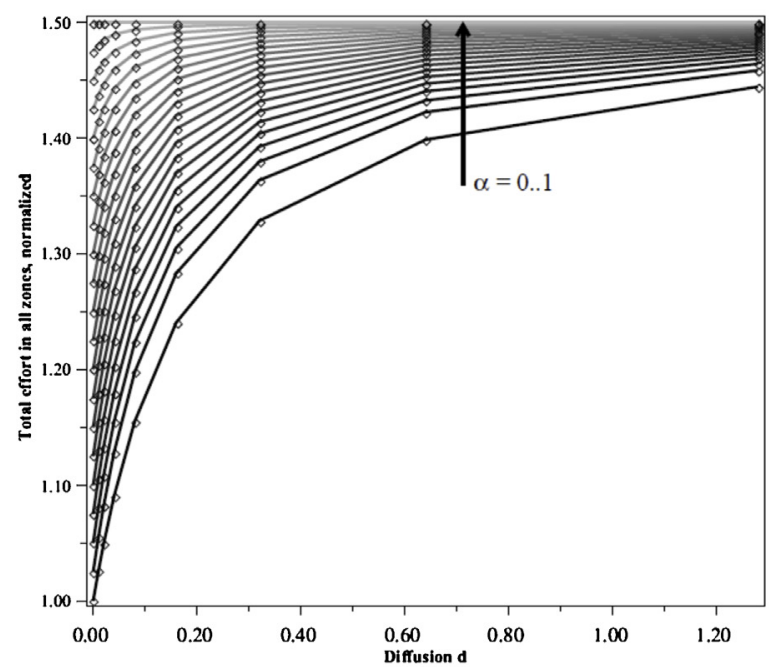

b) Total Payoff

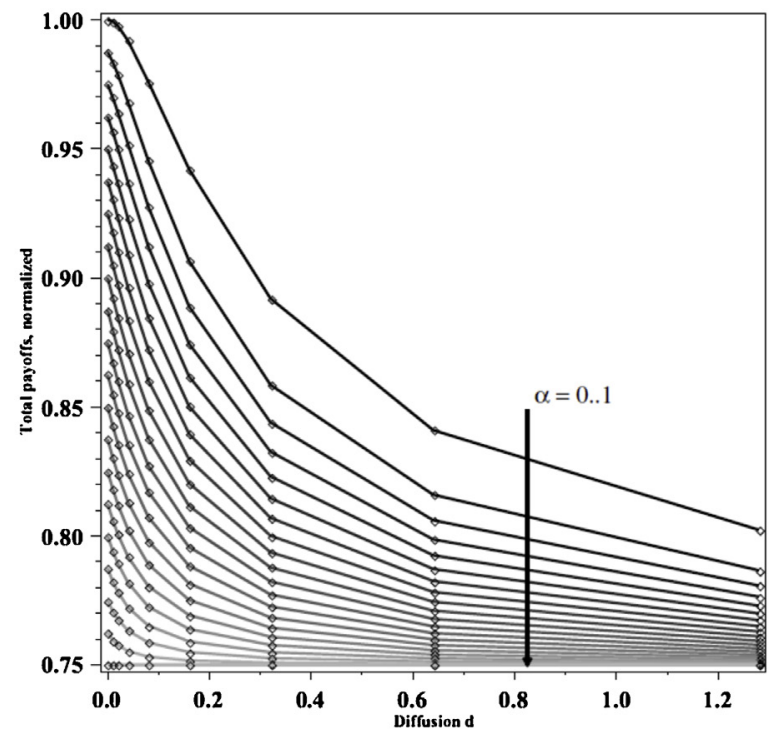

Fig. 2. The Effect of Socially Constructed and Technical Excludability on Total Effort and Payoff under No Cooperation*.

*Efforts and payoffs are expressed in relation to the social optimum which is being set to 1 . Efforts and payoffs in the social optimum are independent of $d$ and $\alpha$. The allocation parameter is varied from $\alpha=0$ to $\alpha=1$ (see arrow). For the cost and growth parameter base case values are assumed ( $c=0.5$ and $r=0.5)$.

scenarios and the non-cooperative scenario become smaller. Thus, the need for cooperation decreases in the cost parameter $c^{28}$

Also Result $3 \mathrm{~b}$ is in line with intuition. A high growth rate encourages fishing and is associated with an economic advantage. However, higher fishing efforts do not necessarily imply lower stocks as the resource recovers more quickly with a high growth rate $r$. Only if diffusion is irrelevant, e.g. there is full cooperation or the entire fishing area is public $(\alpha=1)$, a higher

\footnotetext{
${ }^{28}$ It may be worthwhile to recall that not the absolute value of $c$ matters but the ratio $c / p$. Thus, a higher $c$ has the same effect as a lower price $p$ or a lower catchability coefficient $q$, measuring the technological efficiency of harvesting fish. Hence, a high price and technological efficiency are detrimental to the ecological system but are conducive to economic rents and make cooperation particularly valuable from a normative point of view.
} 
growth rate is exactly balanced by higher fishing efforts and hence the equilibrium stock remains constant. ${ }^{29}$ However, if diffusion matters, e.g., there is no full cooperation, then the growth effect is stronger than the exploitation effect. Consequently, stocks and also payoffs increase with growth parameter $r$ - our measure of rivalry - but the need for cooperation decreases as measured by relative differences.

\section{Results: first stage of coalition formation}

In this section, we analyze stability of coalitions. We are interested whether and under which conditions full or partial cooperation could be a stable. We start by considering the first-best solution of full cooperation, corresponding to the social optimum.

\section{Result 4: stability of cooperation}

a) The incentive to leave the grand coalition is always positive, except for $\alpha=0$ and $d=0$, irrespective of the values of $c$ and $r$. However, if $\alpha=0$ and $d=0$, then there is no gain from cooperation. The incentive to leave increases in $\alpha$ and $d$.

b) The incentive to leave the two-player coalition is generally positive. Only for sufficiently small values of $\alpha$ and $d$, there is a range of parameter values for which partial cooperation is stable. This range increases in the cost parameter $c$ and the growth parameter $r$.

Result 4a is discouraging. Not only because full cooperation is never stable but also because the free-riding incentive is particularly pronounced under those conditions when it would matter most. This follows immediately from Result 2, which states that cooperation would be most desirable in the case of a strong externality as expressed by a large share of the public domain, corresponding to a high value of $\alpha$ and a high diffusion coefficient $d$.

It is evident that $\alpha=0$ and $d=0$ is a special case: there is no common property, and there is no diffusion between EEZs. Due to the lack of interdependency, there is no externality and hence full, no and partially cooperative fishing efforts coincide. Consequently, the incentive to deviate is zero but there is also no gain from cooperation.

In order to understand better the underlying driving forces of Result 4b, Fig. 3 has a closer look at the stability of a twoplayer coalition for various values of the parameters $\alpha$ and $d$. The fact that the grand coalition is never internally stable, allows us to conclude (for symmetric players) that a two-player coalition is always externally stable. Hence, Fig. 3a focuses on internal stability. Internal stability holds for all parameter combinations for which the incentive to leave a two-player coalition is non-positive.

There are two countervailing effects. On the one hand, the larger $\alpha(d)$, the lower the degree of socially constructed (technical) excludability, the larger would be the gains from cooperation. On the other hand, with increasing $\alpha(d)$, also the incentive to deviate sharply increases because the strategic interaction between players increases. Overall, a two-player coalition will only be internally stable, if $\alpha$ and $d$ are sufficiently small.

A closer analysis of intermediate values illustrated in Fig. $3 \mathrm{~b}$ reveals that cooperation fails whenever $\alpha \geq 0.02$ or $d \geq 0.32$ for the base values of the cost parameter $(c=0.5)$ and the growth parameter $(r=0.5)$. The boundary value for $d$ increases in $c$ and $r$. Higher production costs discourage fishing (see Result 3a), and therefore lower the free-riding incentive and increase the upper bound of $d$ for which partial cooperation is stable. Higher growth rates have a positive effect on stock levels (see Result 3b), and therefore lower free-riding incentives and hence also push the upper bound of $d$ up for which partial cooperation is stable. Thus, the lower the degree of rivalry, the higher the likelihood of a stable coalition. However, even for high values of $c$ and $r$, the range of stability remains rather small. Raising both base values of $c$ and $r$ from 0.5 to the maximum value 0.75 considered in our simulations, cooperation fails whenever $\alpha \geq 0.02$ or $d \geq 0.72$, corresponding to the larger triangle in Fig. 3b.

\section{Results of the entire game}

\subsection{Benefit-cost duality of public good and common pool resource games}

Sandler and Arce (2003) showed the duality between public goods and common pool resources. In other words, one problem can be transformed into the other. Hence, in both settings players have an incentive to free-ride which results in the underprovision of the public and the overuse of the common pool resource. Nevertheless, the authors informally conjectured that it would be easier to establish joint action for the former than the latter. In our model the degree of rivalry is approximated through the growth rate $r$. Public good type of games, with a low degree of rivalry, are associated with high values of the parameter $r$, and common pool type of games, with a high degree of rivalry, are captured by low values of the parameter $r$. In our model if the degree of socially constructed and technical excludability is not extremely high, the most

\footnotetext{
${ }^{29}$ Recall that we consider only steady states for which it can be shown analytically that the socially optimal fishing effort exactly offsets any increase in the growth rate in terms of stock level.
} 


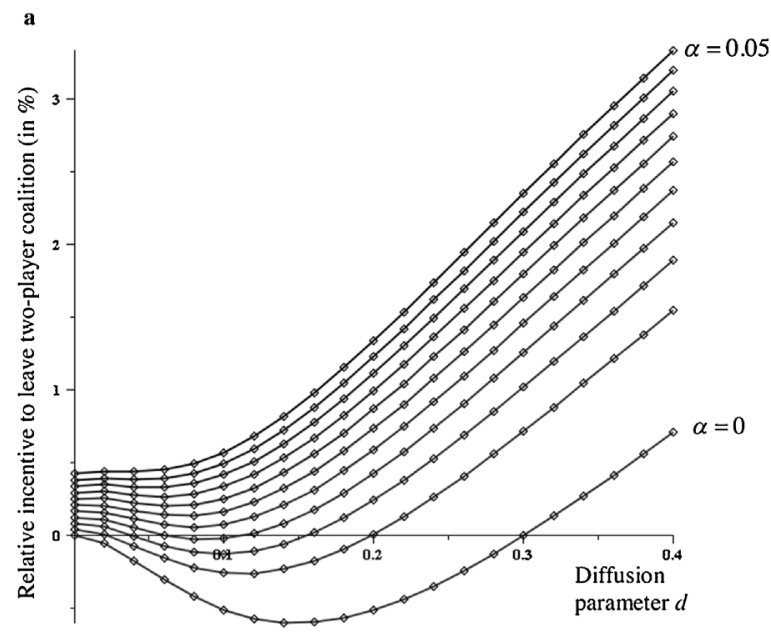

b

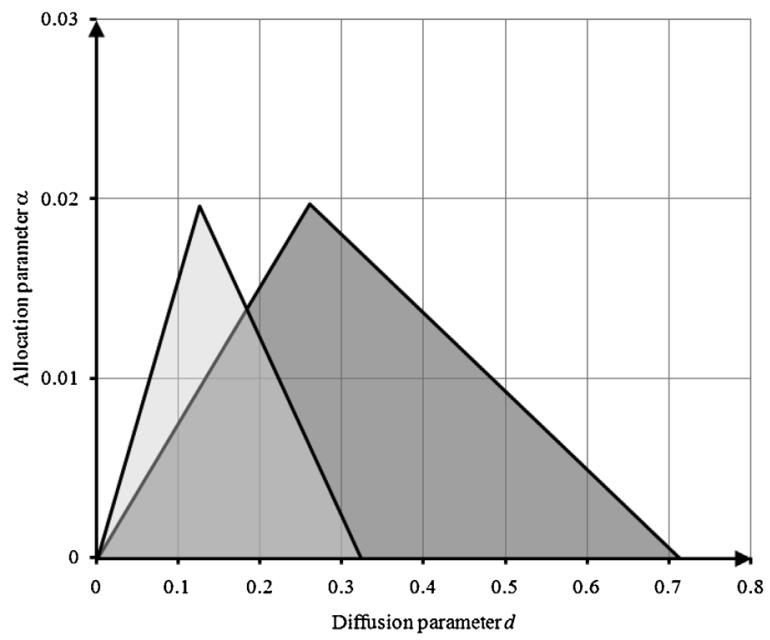

Fig. 3. (a) Incentive to Leave a Two-player Coalition*.

*The incentive to deviate is expressed as a percentage of the payoff of a coalition member. i.e., $100 \bullet\left[\Pi_{i}^{*}(S\{i\})-\Pi_{i}^{*}(S)\right] / \Pi_{i}^{*}(S)$. For the cost and growth parameter base case values are assumed $(c=0.5$ and $r=0.5)$.

(b) Stability of the Two-player Coalition in Parameter Space*.

*Both triangles define parameter combinations $(d, \alpha)$ for which the two-player coalition is stable. The smaller, light shaded triangle refers to base case values for the cost and growth parameter $(c=0.5$ and $r=0.5$ ) whereas the larger, dark shaded triangle corresponds to the conditions that are most favorable for cooperation ( $c=0.75$ and $r=0.75)$.

natural feature associated with the terms "pure public" and "pure commons", no cooperation is the only stable outcome, regardless of the value of $r$ (Result 4). Hence, in terms of establishing cooperation, the duality between public goods and common pool resources holds: no cooperation is the equilibrium. However, in this non-cooperative equilibrium, there are differences. Payoffs and stocks increase with the growth rate $r$ and the relative difference between no and full cooperation becomes smaller (Result 3b). Hence, in this sense, Sandler and Arce's conjecture that public goods lead to less pessimistic outcomes than common pool resources may be viewed as being partially confirmed. This is also true if we consider the limiting case in which the degree of socially constructed and technical excludability is very high: a high value of $r$ may make partial cooperation possible whereas this may not be possible for a low value of $r$ (Result 4). However, with a high growth rate $r$, the relative difference between no and partial cooperation diminishes (Result 3b). Moreover, the limiting case means that the public good can no longer be viewed as a pure but as an impure public good, and the common pool resource is no longer "purely common" but highly privatized. 


\subsection{The paradox of cooperation}

In his paper on international environmental agreements, Barrett (1994) coined the term "paradox of cooperation". He showed that whenever cooperation would be needed most from a global perspective, i.e., the relative difference in terms of global payoffs between full and no cooperation is large, stable coalitions achieve relatively little. In Barrett's model, this difference is related to the benefit-cost ratio of providing the pure public good "emission abatement". In our model, something similar holds: the benefit parameter is de facto the price $p$ and the cost parameter is $c$. More specifically, we argued that only the ratio $c / p q$ is important for results, with $q$ being the catchability coefficient. We showed that the higher this ratio, the higher are stocks regardless of the degree of cooperation (Result 3a), the higher are the chances to establish at least partial cooperation (Result $4 \mathrm{~b}$ ), but the lower are economic rents and the relative global gains from partial and full cooperation (Result 3a).

Because our model is richer than Barrett's model, we could also test the paradox of cooperation regarding other dimensions. Partial and full cooperation would make a substantial difference compared to no cooperation whenever the public domain of the resource is large (large values of $\alpha$ ) and the migration of fish stocks is large (high values of $d$ ) (Result 2). However, exactly under these conditions not even partial cooperation is stable (Result $4 \mathrm{~b}$ ), letting alone full cooperation (Result 4a).

Finally, our results indicate that the higher the growth rate (which is inversely related to the degree of rivalry), the less vulnerable a stock is to overexploitation and the higher are economic rents irrespective of the degree of cooperation (Result 3b). Hence, economic and ecological interests coincide. Moreover, the higher the growth rate, the higher are the chances to establish at least partial cooperation (Result 4b). Despite this, the paradox of cooperation does not completely disappear as the need for cooperation becomes smaller with a high growth rate (Result $3 b$ ).

\section{Extensions}

\subsection{Exclusion of non-members of fishing in the high seas}

There have been continuous efforts to make RFMO membership (or at least compliance with RMFO regulation) mandatory. That is, RFMOs could exclude non-members from fishing in the high seas areas under their jurisdiction, as for instance suggested by the International Plan of Action to Prevent, Deter and Eliminate Illegal, Unreported and Unregulated Fishing (FAO, 2001). In fact, Art. 8(4) of the 1995 UN Fish Stocks Agreement states that "Only those States which are [RFMO] members [...] shall have access to the [respective] fishery resources." However, this provision and similar attempts to enforce RFMO regulations have always been highly controversial as they are obviously inconsistent with the freedom of the high seas set forth in Art. 87, UNCLOS 1982. Nonetheless, we will briefly discuss how our results would change if exclusion of non-members was possible. ${ }^{30}$

Note that equilibrium fishing efforts, stocks and payoffs remain unaffected under full cooperation (as there are no outsiders to be excluded), as well as under no cooperation (as we assume that an RFMO needs at least two members to be able to enforce its regulation in the high seas). Thus, we only have to consider partial cooperation where we have to set $E_{H S_{j}}=0$ for $j \notin S$ when solving the first order conditions in (4) and (5). This implies that the payoffs of members in a two-player coalition increase whereas the payoff of a non-member decreases through this measure. Consequently, leaving the grand coalition or a two-player coalition becomes less attractive. Moreover, the aggregate payoff over all players of a two-player coalition is larger with than without exclusion because equilibrium stock levels are higher.

\section{Result 5: coalition stability with exclusion of non-members}

If exclusion of non-members from fishing in the high seas is possible, then

a) the grand coalition is stable for a wide range of parameter values (Result 4a does not hold any more);

b) the parameter space for which the two-player coalition is stable is significantly larger than without exclusion (modification of Result 4b);

c) the parameter space for which partial and full cooperation is stable increase with $\alpha$ (Result 4 is reversed);

d) There always exists a value of $\alpha$ above which partial or full cooperation is stable, irrespective of the value of $d$ (different from Result 4).

These results are illustrated in Fig. 4, which shows the areas in parameter space for which the two-player and the grand coalition are stable.

\footnotetext{
${ }^{30}$ Note that this setting does not correspond to establishing nature reserves with a ban on fishing in this reserve as considered for instance by Costello and Kaffine (2009); Sanchirico and Wilen (2001); Smith et al. (2010) and White and Costello (2014). In our setting, only the non-members of the RFMO are not allowed to fish in the high seas.
} 


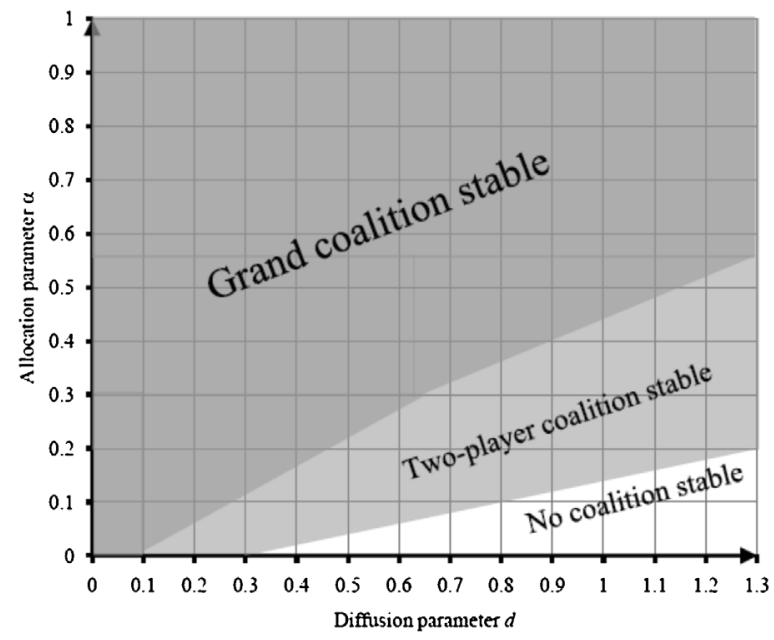

Fig. 4. Stability of Coalitions in Parameter Space with Exclusion*.

*The shaded areas indicate parameter combinations $(d, \alpha)$ for which the respective coalition is stable if exclusion of non-members from fishing in the high seas is possible. Note that whenever the grand coalition is stable, the two-player coalition is externally unstable. Base case parameter values are assumed $(c=0.5$ and $r=0.5)$.

Clearly, the possibility to evict non-cooperating fishing states from the high seas is beneficial for the stability of cooperation. Not only partial but also full cooperation is possible. Interestingly, the role of the allocation parameter $\alpha$ is reversed. Without exclusion, already partial cooperation fails whenever $\alpha$ is sufficiently large, whereas with exclusion, even the grand coalition turns out to be stable for large values of $\alpha$. A large common pool area (high values of $\alpha$ ) implies large exclusive benefits to coalition members but low free-riding benefits to outsiders if exclusion is possible. The larger the degree of technical non-excludability, the larger should be the area managed by the RFMO. Obviously, this scenario assumes a substantial amount of enforcement-power of RFMOs, most likely an overly optimistic view regarding future enforcement of international law.

\subsection{Coalition formation process}

Our definition of stability of coalitions, internal and external stability, is associated with two assumptions: open membership and a simultaneous decision about membership. Hence, we ask whether exclusive membership and/or a sequential coalition formation process would make a difference. Exclusive membership could make a difference if a partial agreement is internally stable, and an outsider would like to join, and hence the agreement would not be externally stable under open membership. Under exclusive membership, the current members would only accept accession if they were better off in the enlarged coalition. For our standard assumption it turned out that only a two player coalition was stable and hence we can conclude that an outsider does not have incentive to join in order to form the grand coalition. Thus, exclusive membership would not make a difference.

Consider a sequential coalition formation process. For our standard assumption, this can make no difference as the largest possible stable coalition is only a two-player coalition. Hence, our results are also robust with respect to this alternative assumption.

\subsection{Sink-source migration patterns}

In this subsection, we briefly discuss the implications of a sink-source model. As pointed out above and illustrated in Fig. $1 \mathrm{~b}$ and c, we consider two simple cases. In case 1 , we assume the high seas to be the source and in case 2 this is reversed. We do not consider diffusion between EEZs, which could be a possibility, in particular in case 2, but this would not change the basic conclusion on which we report below.

Diffusion is now uni-directional, and the strength depends apart from the stock in the source on the diffusion parameter $d$. It is clear that now the growth rate in the source must exceed diffusion as otherwise no interior equilibrium exists with positive efforts in all zones. With reference to Table 3, for the different values of the growth parameter $r$, we need to assume that the largest value of $d$ must be smaller than $r$, at least by a small amount. It is also clear that neither $\alpha=0$ nor $\alpha=1$ would make sense in a sink-source model and hence we consider $\alpha \in[0.05,0.95]$ with the same step sizes as reported above in Section 4.3.

In a sink-source model, and different from the density-dependent model, parameter $\alpha$, measuring the relative patch sizes can no longer be viewed as only defining property rights, it also influences the biology. If the high seas are the source for instance, a large value of $\alpha$ does not only mean that the publicly accessible fishing ground is large compared to the 
only privately accessible EEZs, but also that the source is relatively large compared to the sink. Consequently, we consider different values for $\alpha$ in our simulations to check the robustness of our conclusions, but do not conduct a comparative static analysis with respect to this parameter. In the subsequent discussion, we focus on the impact of the diffusion parameter $d$ on outcomes.

The larger diffusion, the lower will be equilibrium efforts and stocks (and hence effort density and stock densities) in the source and for the sink this is reversed. This holds for all scenarios of cooperation, full, partial and no cooperation.

If the high seas is the source, cooperation only requires coordination of strategies in the high seas, as we assume no diffusion between EEZs (and thus no externality from fishing in the EEZs). Like in the fully integrated model with densitydependent diffusion, cooperation implies to reduce fishing efforts in the high seas, either by all players (full cooperation) or by a two-player coalition. As long as there is not full cooperation, the non-member will increase his fishing efforts above non-cooperative levels, as this is true for the density-dependent model. We find that the incentive to leave the grand coalition and a two-player coalition decreases in the diffusion parameter $d$. The reason is that a large value of $d$ shifts efforts and stocks from the high seas to the EEZs which are not subject to free-riding. However, the incentive to leave is always positive, in the grand coalition and in a two-player coalition for all parameter constellations, which we consider in our simulations.

If the EEZs are the source, cooperation requires to coordinate strategies in all zones. Again, the non-member will increase efforts compared to non-cooperative levels, contradicting the efforts of the two-player coalition to protect stock levels. The effect of diffusion on the incentive to free-ride is now reversed, but for the same reason. A high diffusion means a shift of efforts and stocks to the high seas, which is exploited by all players and hence implies a high free-rider incentive. Again, no agreement is stable for all simulations, regardless whether this entails full or partial cooperation.

Taken together, asymmetric diffusion patterns reduce the prospects of forming stable agreements, which were already not very encouraging in the symmetric density-dependent diffusion model (Result 4), at least as long as non-members of an RFMO cannot be excluded from fishing in the high seas (Result 5).

\section{Concluding remarks}

We presented the first model that tests for the stability of RFMOs which captures different economic zones and the migration of fish stocks. This allowed us to analyze how the degree of socially constructed and technical excludability impacts on the success of impure public good and common pool resource agreements. The model was highly stylized but provides a conceptual blueprint for extensions. Among other things, it neglected administrative and enforcement cost associated with establishing RFMOs and hence overestimated the prospect to depart from non-cooperative fishing efforts. One obvious extension of our model could look at different migration patterns of fish stocks and their impact on the success of RFMOs, like the multiple-source and the spatially linear model as mentioned in Sanchirico and Wilen (1999). Another extension could include marine reserves, along the lines of Punt et al. (2013), but allowing for different stock densities across zones as for instance in Costello and Kaffine (2009); Sanchirico and Wilen (2001) and Smith et al. (2010). From our sink-source model it also became apparent that it would be important to search for a modelling approach such that in asymmetric biological environments, patch size and access rights can be disentangled. Most likely, this would require to model stock density to vary within a patch or to consider continuous density gradients. Finally, it would be worthwhile to depart from a steady-state analysis and consider a fully dynamic model of coalition formation in order to capture how membership in an RFMO may vary over time depending on the development of the fish stock, including regime shifts. However, as mentioned above, such a model with multiple zones and migration would be extremely complex and is therefore left for future research.

\section{Declaration of Competing Interest}

The authors declare that they have no known competing financial interests or personal relationships that could have appeared to influence the work reported in this paper.

\section{Acknowledgment}

The third author acknowledges financial support from the Portuguese Foundation for Science and Technology Grant $\mathrm{UID} / \mathrm{ECO} / 04007 / 2019$.

\section{Appendix A. Supplementary data}

Supplementary material related to this article can be found, in the online version, at doi:https://doi.org/10.1016/ j.reseneeco.2019.101122.

\section{References}

Armstrong, C.W., Skonhoft, A., 2006. Marine reserves: a bio-economic model with asymmetric density dependent migration. Ecol. Econ. 57 (3), 466-476. Barrett, S., 1994. Self-enforcing international environmental agreements. Oxf. Econ. Pap. 46, 878-894.

Bloch, F., 2003. Non-cooperative models of coalition formation in games with spillovers. In: Carraro, C. (Ed.), The Endogenous Formation of Economic Coalitions. Edward Elgar, Cheltenham, UK. 
Carraro, C., Siniscalco, D., 1993. Strategies for the international protection of the environment. J. Public Econ. 52, 309-328.

Clark, C.W., 2010. Mathematical Bioeconomics - the Mathematics of Conservation, $3^{\text {rd }}$ edition. Wiley, Hoboken, New Jersey.

Cornes, R., Sandler, T., 1994. The comparative static properties of the impure public good model. J. Public Econ. 54, 403-421.

Costello, C., Kaffine, D.T., 2009. Marine protected areas in spatial property-rights fisheries. Aust. J. Agric. Resour. Econ. 54, 321-341.

Costello, C., Polasky, S., 2008. Optimal harvesting of stochastic spatial resources. J. Environ. Econ. Manage. 56, 1-18.

Crutchfield, J., 1964. The marine fisheries: a problem of international cooperation. Am. Econ. Rev. 54, $207-218$.

d'Aspremont, C., Jacquemin, A., Gabszewicz, J.J., Weymark, J.A., 1983. On the stability of collusive price leadership. Can. J. Econ. 16, 17-25.

de Zeeuw, A.J., 2008. Dynamic effects on the stability of international environmental agreements. J. Environ. Econ. Manage. 55 (2), $163-174$.

Eyckmans, J., Finus, M., 2006. Coalition formation in a global warming game: how the design of protocols affects the success of environmental treaty-making. Nat. Resour. Model. 19, 323-358.

Eyckmans, J., Tulkens, H., 2003. Simulating coalitionally stable burden sharing agreements for the climate change problem. Resour. Energy Econ. 25, 299-327.

FAO Fisheries and Aquaculture Department, 2001. International Plan of Action to Prevent, Deter and Eliminate Illegal, Unreported and Unregulated Fishing, Rome, Italy.

FAO Fisheries and Aquaculture Department, 2010. The State of World Fisheries and Aquaculture 2010, Rome, Italy.

FAO Fisheries and Aquaculture Department [online], [accessed 17 October 2012], http://www.fao.org/fishery/rfb/search/en, Rome, Italy 2012. Regional Fishery Bodies (RFB) - Web Site, Updated 20 October 2008.

Finus, M., Caparrós, A., 2015. Handbook on Game Theory and International Environmental Cooperation: Essential Readings. Edward Elgar, Cheltenham, UK.

Finus, M., Rundshagen, B., 2006. Participation in international environmental agreements: the role of timing and regulation. Nat. Resour. Model. 19, $165-200$.

Finus, M., Tjøtta, S., 2003. The Oslo Protocol on sulfur reduction: the great leap forward? J. Public Econ. 87, 2031-2048.

Finus, M., Rundshagen, B., Eyckmans, J., 2014. Simulating a sequential coalition formation process for the climate change problem: first come, but second served? Ann. Oper. Res. 220, 5-23.

Flaaten, O., Mjølhus, E., 2005. Using reserves to protect fish and wildlife - simplified modelling approaches. Nat. Resour. Model. 18, 157-182.

Gordon, H., 1954. The economic theory of a common property resource: the fishery. J. Polit. Econ. 62, 124-142.

Hannesson, R., 1997. Fishing as a supergame. J. Environ. Econ. Manage. 32, 309-322.

Hannesson, R., 1998. Marine reserves: what would they accomplish? Mar. Resour. Econ. 13, 159-170.

High Seas Task Force, 2006. Closing the Net: Stopping Illegal Fishing on the High Seas. Governments of Australia, Canada, Chile, Namibia, New Zealand, and the United Kingdom, WWF IUCN and the Earth Institute at Columbia University.

Kaul, I., Mendoza, R.U., 2003. Advancing the concept of public goods. In: Kaul, I. (Ed.), Providing Global Public Goods: Managing Globalization. Oxford University Press, Oxford, UK.

Kennedy, J., 2003. Scope for efficient multinational exploitation of North-East Atlantic Mackerel. Mar. Resour. Econ. 18, 55-80.

Kvamsdal, S.F., Sandal, L.K., 2008. The premium of marine protected areas: a simple valuation model. Mar. Resour. Econ. 23, 171-197.

Kwon, O., 2006. Partial international coordination in the great fish war. Environ. Resour. Econ. 33, 463-483.

Lindroos, M., 2004. Sharing the benefits of cooperation in the Norwegian spring-spawning herring fishery. Int. Game Theory Rev. 6, 35-54.

Lindroos, M., 2008. Coalitions in international fisheries management. Nat. Resour. Model. 21, 366-384.

Lodge, M., Anderson, D., Lobach, T., Munro, G., Sainsbury, K., Willock, A., 2007. Recommended Best Practices for Regional Fisheries Management Organizations: Report of an Independent Panel to Develop a Model for Improved Governance by Regional Fisheries Management Organizations, Chatham House, London, UK.

Long, L.K., Flaaten, O., 2011. A Stackelberg analysis of the potential for cooperation in straddling stock fisheries. Mar. Resour. Econ. 26, 119-139.

Mäler, K.-G., 1994. Acid rain in Europe: a dynamic perspective on the use of economic incentives. In: Folmer, H., van Ierland, E. (Eds.), International Environmental Economics. Elsevier, Amsterdam, The Netherlands.

Markandya, A., Rübbelke, D., 2004. Ancillary benefits of climate policy. Jahrbuch Nationalökonomie und Statistik 224, 488-503.

McCarthy, N., Sadoulet, E., de Janvry, A., 2001. Common pool resource appropriation under costly cooperation. J. Environ. Econ. Manage. 42, 297-309.

McGinty, M., 2007. International environmental agreements among asymmetric nations. Oxf. Econ. Pap. 59, 45-62.

McWhinnie, S.F., 2009. The tragedy of the commons in international fisheries: an empirical examination. J. Environ. Econ. Manage. 57, 321-333.

Meltzer, E., 1994. Global overview of straddling and highly migratory fish stocks: the non-sustainable nature of high seas fisheries. Ocean. Dev. Int. Law 25 (3), 255-344.

Mesterton-Gibbons, M., 1993. Game-theoretic resource modelling. Nat. Resour. Model. 7, 93-147.

Miller, S., Nkuiya, B., 2016. Coalition formation in fisheries with potential regime shift. J. Environ. Econ. Manage. 79, 189-207.

Munro, G.R., 1982. Fisheries, extended jurisdiction and the economics of common property resources. Can. J. Econ. 15 (3), 405-425.

Munro, G.R., van Houtte, A., Willmann, R., 2004. The Conservation and Management of Shared Fish Stocks: Legal and Economic Aspects, FAO Fisheries Technical Paper No. 465, Rome.

Musgrave, R., 1959. The Theory of Public Finance. McGraw Hill, New York, NJ.

Nøstbakken, L., 2006. Regime switching in a fishery with stochastic stock and price. J. Environ. Econ. Manage. 51, $231-241$.

Ostrom, E., 1990. Governing the Commons: The Evolution of Institutions for Collective Action. Cambridge University Press, Cambridge, UK.

Pezzey, J.C.V., Roberts, C.M., Urdal, B.T., 2000. A simple bioeconomic model of a marine reserve. Ecol. Econ. 33, 77-91.

Pintassilgo, P., Lindroos, M., 2008. Coalition formation in straddling stock fisheries: a partition function approach. Int. Game Theory Rev. 10, 303-317.

Pintassilgo, P., Grønbæk, L., Lindroos, M., 2015. International fisheries agreements: a game theoretical approach. Environ. Resour. Econ. 62, 689-709.

Pintassilgo, P., Finus, M., Lindroos, M., Munro, G., 2010. Stability and success of regional fisheries management organizations. Environ. Resour. Econ. 46, 377-402.

Punt, M.J., Weikard, H.P., Van Ierland, E.C., 2013. Marine protected areas in the high seas and their impact on international fishing agreements. Nat. Resour. Model. 26, 164-193.

Rubio, S.J., Casino, B., 2005. Self-enforcing international environmental agreements with a stock pollutant. Spanish Econ. Rev. 7, 89-109.

Rubio, S.J., Ulph, A., 2007. An infinite-horizon model of dynamic membership of international environmental agreements. J. Environ. Econ. Manage. 54 (3), 296-310.

Sampson, G.S., Sanchirico, J.N., 2019. Exploitation of a mobile resource with costly cooperation. Environ. Resour. Econ. 73 (4), $1135-1163$.

Samuelson, P.A., 1954. The pure theory of public expenditure. Rev. Econ. Stat. 36, 387-389.

Sanchirico, J.N., Wilen, J.E., 1999. Bioeconomics of spatial exploitation in a patchy environment. J. Environ. Econ. Manage. 37, 129-150.

Sanchirico, J.N., Wilen, J.E., 2001. A bioeconomic model of marine reserve creation. J. Environ. Econ. Manage. 42, 257-276.

Sanchirico, J.N., Wilen, J.E., 2005. Optimal spatial management of renewable resources: matching policy scope to ecosystem scale. J. Environ. Econ. Manage. 50, 23-46.

Sandler, T., 1998. Global and regional public goods: a prognosis for collective action. Fisc. Stud. 19, 221-247.

Sandler, T., Arce, D., 2003. Pure public goods versus commons: benefit-cost duality. Land Econ. 79, 355-368.

Schaefer, M.B., 1954. Some aspects of the dynamics of populations important to the management of the commercial marine fisheries. Bull. Inter-Am. Trop. Tuna Commission 1, 25-56.

Smith, M.D., Lynham, J., Sanchirico, J.N., Wilson, J.A., 2010. Political economy of marine reserves: understanding the role of opportunity costs. Proc. Natl. Acad. Sci. 107, 18300-18305.

Stavins, R.N., 2011. The problem of the commons: still unsettled after 100 years. Am. Econ. Rev. 101, 81-108. 
Tarui, N., Mason, C.F., Polasky, S., Ellis, G., 2008. Cooperation in the commons with unobservable actions. J. Environ. Econ. Manage. 55, 37-51.

White, C., Costello, C., 2014. Close the high seas to fishing? PLoS Biol. 12 (3), http://dx.doi.org/10.1371/journal.pbio.1001826.

Willock, A., Lack, M., 2006. Follow the leader: learning from experience and best practice in regional fisheries management organizations. WWF Int. TRAFFIC Int.

Yi, S.-S., 1997. Stable coalition structures with externalities. Games Econ. Behav. 20, 201-237. 